\title{
"VIVIR LA INFANCIA EN TIEMPOS DE GUERRA". UN PROYECTO DE INNOVACIÓN CON FUENTES ORALES EN EL ÁMBITO UNIVERSITARIO ${ }^{1}$
}

\author{
Live Childhood in Times of War. A Research Project \\ with Oral Sources in the University Scope
}

\author{
Miriam Sonlleva Velasco \\ miriam.sonlleva@uva.es \\ Universidad de Valladolid. España \\ Carlos Sanz Simón \\ csa02@ucm.es \\ Universidad Complutense de Madrid. España \\ Fecha de recepción: 01/03/2019 \\ Fecha de aceptación: 11/06/2019
}

RESUMEN: En el presente artículo mostramos una experiencia práctica llevada a cabo con 83 estudiantes de la Facultad de Educación de Segovia, nacida del Proyecto de Innovación Docente Memoria de la escuela contemporánea: fuentes orales, iconográficas y otros recursos pedagógicos para la formación docente de la Universidad de Valladolid. El objetivo de esta experiencia es superar la visión de la historia de la educación entendida como una disciplina del pasado, para pasar a establecer un diálogo entre la educación pretérita y la actual. Para ello, formamos a nuestros estudiantes de Magisterio en el uso de fuentes orales, desde las que tratamos de recuperar la experiencia de personas de la provincia de Segovia que vivieron su infancia durante el periodo de la Guerra Civil Española (1936-1939). El proyecto, titulado Vivir la infancia en tiempos de guerra, trata de ofrecer a los docentes en formación una visión de lo que significó este periodo de nuestra historia reciente para los menores que sufrieron el hambre, la muerte y la escasez de recursos personales y materiales. Asimismo, les invita a conocer el papel que jugaron la familia y la escuela como agentes educativos de primer orden en aquellos años; y a construir una mirada crítica sobre los usos y abusos políticos de la historia. Los resultados de la experiencia muestran cómo el uso de

1 El presente trabajo se ha realizado gracias a la concesión de un contrato predoctoral de personal investigador en formación de la Universidad Complutense de Madrid (CT17/17CT18/17) cofinanciado por el Banco Santander. 
estas fuentes es una herramienta imprescindible para despertar la mirada crítica de los estudiantes hacia nuestro pasado y mejorar su conocimiento sobre la historia de la educación española del siglo XX.

Palabras clave: Formación Docente; Guerra Civil; Historia de la Educación; Oralidad; Proyecto de Investigación.

ABSTRACT: In the present article we show a practical experience carried out with 83 students of the Faculty of Education of Segovia. The experience is part of the project of Teaching Innovation Memory of the contemporary school: oral sources, iconographic and other pedagogical resources for the teacher training of the University of Valladolid. The objective of this experience is to overcome the vision of the history of education, understood as a discipline of the past, in order to establish a dialogue between past and current education. To do this, we train our trainee teachers in the use of oral sources, from which we try to recover the experience of people from the province of Segovia who lived their childhood during the period of the Spanish Civil War (1936-1939). The title of the project is «To live childhood in times of war», tries to offer teachers in formation a vision of what this period of our recent history meant for children who suffered hunger, death and lack of personal and material resources. Likewise, it invites them to know the role played by the family and the school as first-class educational agents in those years; and to build a critical view of the political uses and abuses of history. The results of the experience show how the use of these sources is an essential tool to awaken the critical look of students towards our past and improve their knowledge about the history of Spanish education of the 20th century.

Keywords: Teacher Education; Civil War; History of Education; Orality; Research Project.

SUMARIO: 1. La memoria como ejercicio necesario para conectar pasado, presente y futuro. 2. Las fuentes orales como recurso para la enseñanza. 2.1. El síndrome de Damocles en las fuentes históricas tradicionales. 2.2. Potencialidades de la historia oral en el ámbito educativo. 2.3. Proyectos de historia oral en el nivel universitario. 3. Enseñar la Historia de la Educación a través de fuentes orales. Un proyecto de innovación docente. 4. El proyecto «Vivir la infancia en tiempos de guerra». 4.1. Descripción, contexto y objetivos. 4.2. Diseño y secuenciación del proyecto. 5. Apuntes metodológicos. 5.1. Fases de la investigación. 5.2. Participantes. 5.3. Instrumentos para la recogida de datos. 5.4. Análisis de los datos. 6. Resultados. 6.1. Influencia del proyecto en el conocimiento de los estudiantes sobre la vida y la educación en el periodo de la Guerra Civil española. 6.1.1. Conocimiento de las repercusiones de la Guerra Civil en el colectivo infantil. 6.1.2. Valoración sobre la influencia de la familia en la educación de la infancia. 6.1.3. Influencia de la escuela en la identidad de la infancia durante la Guerra Civil. 6.1.4. Importancia del proyecto para la comprensión de la pérdida de derechos e indefensión de la infancia ante una ofensiva. 6.1.5. Conocimiento de la educación española a lo largo del siglo xx. 6.2. Visión general y aprendizajes de la práctica realizada. 6.2.1. Aprendizajes de la práctica realizada. 6.2.2. Sentimientos provocados tras la realización de la entrevista oral. 6.2.3. Relaciones del proyecto con el futuro profesional de los maestros en formación. 7. Algunas conclusiones sobre la experiencia. 8. Referencias bibliográficas.

\section{LA MEMORIA COMO EJERCICIO NECESARIO PARA CONECTAR PASADO, PRESENTE Y FUTURO}

La enseñanza de la Historia ha estado ligada siempre a una necesaria conexión con el presente y se ha entendido como un medio para replantear y afrontar el futuro con una clara conciencia sobre lo vivido.

Las últimas décadas del siglo Xx presentaron una ruptura con los paradigmas tradicionales en la investigación histórica. Las catástrofes humanas que se vivieron a lo 
largo de la Segunda Guerra Mundial, la Guerra Civil Española, las dictaduras latinoamericanas y el conflicto de la Guerra Fría hicieron de este siglo un campo de batalla de ideas políticas y sociales que se vieron reflejadas en los modos de investigar aquel relato del pasado (Becerra, 2014). Frente a la Historia oficial de estos acontecimientos, escrita por la hegemonía dominante, se ocultaba silenciada -como anunciaba Paul Ricoeur (2004) - una historia manipulada y censurada que mostraba la versión de las víctimas de aquellos conflictos políticos y militares. Pero no fueron pocos los que trataron de ocultarla. Junto a los historiadores que tuvieron cierta inercia por mantener algunos silencios se posicionó un nutrido número de docentes que, a pesar de conocer que la historia que estaba escrita sobre aquel pasado solo representaba a una minoría de la población, siguió transmitiendo el discurso dominante en las aulas.

La enseñanza de una versión del pasado bañada por la injusticia y la falta de verdad, puede considerarse una aberración en términos científicos, didácticos y políticos, pues como detalla Chartier (2007), a través de la misma se ayuda no solo a que la historia oficial haga desaparecer a las víctimas, sino también a sus recuerdos y con ellos parte de la historia. El profesor Enzo Traverso criticaba en uno de sus trabajos cómo tradicionalmente la historiografía se ha presentado no solo como el lugar para la producción de saberes, sino también como el espacio para la reproducción de olvidos. Ciertamente, «cuando los revela, los analiza y los colma, es cuando cumple su función crítica» (Traverso, 2010, p. 80) y se asienta en los pilares de la justicia social.

Laura Benadiba (2007) explica que los docentes tienen la responsabilidad de construir esta memoria que ha sido tradicionalmente silenciada por la historiografía. Como afirma la autora, en la transmisión del pasado se encuentra la llave para comprender el presente y sobre todo para valorarlo desde una conciencia crítica. Estamos convencidos de que si el futuro docente es consciente de la intención que guía su praxis y desarrolla habilidades y actitudes que respondan a una construcción y enseñanza justa del conocimiento, responderá a los objetivos y las expectativas de una historia crítica y asentada en la verdad (Tribó, 2005; Mendioroz-Lacambra, 2016).

La sociedad de nuestros días demanda la necesidad de formar maestros con unos sólidos conocimientos sociales y culturales que permitan responder a los interrogantes de una sociedad en permanente cambio que frecuentemente se olvida de su pasado por la inmediatez del presente. Por ello, uno de los principales retos a los que se enfrentan los docentes universitarios que están formando a los maestros del mañana es, sin duda, explicitar la enseñanza de la Historia más allá de esa explicación multicausal que permite observar, analizar y reflexionar críticamente sobre el pasado, el presente y el futuro; pero también, establecer la relación entre el conocimiento histórico y las innumerables capacidades y valores implícitos que se encuentran en esta área de conocimiento (Andreu, 2017).

La tradición identitaria que enraizó en la enseñanza de la historia en los siglos XIX y $x x$ entendió que los ciudadanos pertenecientes a un Estado-nación se presentaban como un cuerpo homogéneo, que compartía una historia, un territorio y una cultura. 
Algunos estados -como el español-asumieron desde entonces la tarea de internalizar una identidad colectiva mediante la emisión de símbolos para el refuerzo de los sentimientos de pertenencia comunitaria y la instrucción histórica a través de contenidos y efemérides. La enseñanza de la Historia se ha transmitido desde entonces, atendiendo a estos patrones, desde los discursos pedagógicos, los relatos nacionales y los libros de texto (Boyd, 2000, 2013; González, 2006; Valls, 2008).

Son muchos los estudios realizados en los últimos años que revelan la importancia de rescatar la conciencia histórica para la enseñanza de una Historia alejada de hitos y protagonistas oficiales. Para ello, los investigadores exponen que es necesario adentrarse en los debates acerca de la conciencia histórica como actividad práctica, aspecto que implica establecer discusiones intelectuales y prácticas culturales que articulen pasado, presente y futuro. Además, se necesita debatir sobre los sentidos hegemónicos a través de los cuales se ha construido la historia y los procesos de identidad nacional (Pérez, Garguin y Sorgentini, 2017).

Laville (2003) explica que esta corriente de la "conciencia histórica» permite considerar la memoria y la identidad como campos de interés, así como revisar los fundamentos, contenidos y funciones de la educación ciudadana. Cuestionar la enseñanza de la historia desde la "conciencia crítica» permite avanzar en las relaciones entre tiempo histórico y tiempo social, razonar la construcción de identidades y valores y fomentar un pensamiento crítico y reflexivo. Como afirma Tutiaux-Guillón (2003) estos aspectos son imprescindibles para crear en el alumnado una conciencia sobre el pasado y desarrollar en ellos una actitud abierta, tolerante y democrática que se resista a las imposiciones políticas.

Desde este punto de partida y modo particular de entender la historia y de acercarse al pasado, un grupo de docentes e investigadores vinculados con la Educación, iniciamos en el curso 2016/2017 en la Universidad de Valladolid un Proyecto de Innovación Docente que trataba de acercar a nuestros estudiantes hacia una historia de la educación crítica de la mano de fuentes orales. El historiador Peter Burke indicó, en un ejercicio de clarificación sobre el devenir de la Nueva Historia, que los nuevos planteamientos en las formas de hacer Historia deben caracterizarse por huir de las fuentes meramente documentales o normativas y reforzó el ideal de que la historia no puede ser objetiva (Burke, 1999). Nuestra percepción del pasado como sujetos $-\mathrm{y}$ como partes integrantes de colectividades-nos impide concebir la Historia como una creación ajena a los prejuicios y condicionamientos inevitables y, por supuesto, historiables.

Desde este Proyecto de Innovación Docente hemos llevado a cabo a lo largo de estos años varios proyectos en diferentes asignaturas de los Grados de Magisterio de la Universidad de Valladolid, vinculados con la Historia de la Educación. El último de ellos, realizado en el curso académico 2018/2019 y titulado Vivir la infancia en tiempos de guerra, es un claro ejemplo de esa forma de transmitir la historia crítica que planteaba el profesor Traverso. 
Enmarcado en el contexto de la Guerra Civil Española en la provincia de Segovia, tratamos desde sus objetivos que los futuros docentes recojan el relato de quienes vivieron en primera persona este conflicto bélico que ha explicado -y explica- tendencias, políticas, proyectos e ideas que nuestro país hoy afronta. En línea con la idea de Burke (1999), pretendemos a través de este escapar de la historia positivista o normativa basada en los grandes documentos y descender en la realidad histórica, en los estamentos sociales y conocer el testimonio de uno de los sectores más perjudicados de aquella batalla: la infancia. Las consecuencias de aquella batalla, sin duda, trascendieron los tres años que duró el conflicto prolongándose a lo largo de décadas. Pero sus recuerdos han ahogado la memoria de muchos niños y niñas que sufrieron aquella guerra y que sus experiencias vitales quedaron marcadas por una infancia en la que el hambre, la muerte y la represión se convirtieron en sus compañeros de juego.

Conocedores a través de algunos estudios previos de lo ocurrido en aquellos años y sabiendo que la voz de las generaciones que la vivieron se apaga progresivamente, consideramos que era nuestro deber como historiadores de la educación acercar a los estudiantes a esta versión del pasado ¿Y por qué no hacer de estos testimonios el contenido de una asignatura? ¿Por qué no partir de la propia investigación para construir un conocimiento en el que el alumnado sea partícipe? ¿Por qué no hacer que los y las relatoras sean los encargados de hacer Historia y de evidenciar los usos y abusos que se han llevado a cabo con ella?

El presente artículo se propone dar a conocer la experiencia del proyecto Vivir la infancia en tiempos de guerra, realizado por 83 estudiantes de la Facultad de Educación de Segovia y a partir de la misma analizar: 1) la influencia que para ellos ha tenido el proyecto en el conocimiento de la Guerra Civil española y la educación de la infancia en el aquel periodo de nuestra historia reciente; y 2) los sentimientos que les ha generado conocer a través de fuentes orales la historia de un periodo tan convulso como el que vivió España a finales de los años treinta del siglo xx y lo aprendido de este proyecto para su futura profesión.

\section{LAS FUENTES ORALES COMO RECURSO PARA LA ENSEÑANZA}

\subsection{El síndrome de Damocles en las fuentes históricas tradicionales}

Como buenas cortesanas aduladoras de personajes históricos relevantes, las fuentes escritas se han presentado a lo largo de la historia como garantes de la verdad. Su afán por el poder las llevó a convertirse durante siglos en la única forma de acercarse al pasado.

Las minorías selectas no dudaron en aprovecharse de la escritura para ofrecer una visión única del tiempo antiguo en su propio beneficio. Como afirma Paul Thomson, los historiadores, que pertenecían a las clases administrativas y gobernantes, 
se pusieron al servicio de aquel tiempo histórico dividido en reinados y dinastías, en el que las clases trabajadoras -a menos que fueran conflictivas- no fueron consideradas. De este modo, cualquier documento personal, local o extraoficial perdió cualquier posibilidad de ser conservado, pues no tenía ningún valor para la clase dominante (Thompson, 1988, p. 11).

La creación de archivos locales y nacionales siguió esta tendencia de la primacía de lo escrito. Registros de nacimiento y defunción, archivos judiciales, censos, gráficas, actas, expedientes y hasta imágenes y correspondencia privada de las clases dirigentes fueron conservados y custodiados en estos espacios como garantes de la indiscutible y única verdad histórica.

Pero los vertiginosos cambios políticos, económicos y sociales ocurridos en el siglo $x x$ hicieron que la fuente escrita se viera amenazada. El repudio hacia los totalitarismos y autoritarismos que dejaron en aquel contexto a millones de víctimas presas del devenir histórico, hicieron que tomara un valor fundamental para contar lo ocurrido la fuente oral. En torno a ella aparecía la memoria de quienes jamás fueron considerados para contar el pasado. La aparición de la Memoria a través del uso de testimonios de vida como instrumento de análisis social, introdujo nuevos elementos que permitieron reordenar el discurso político precedente jerarquizando a los protagonistas y desalojando de su lugar preferente a las élites del poder (Díaz y Gago, 2006).

A partir de entonces, el relato hegemónico de tiempos pretéritos empezó a sentir el peligro de ver amenazada su credibilidad. La primacía de las fuentes documentales para historiar las épocas precedentes fue desde entonces cediendo terreno a la fuente oral, que avanzaba en la presentación de nuevos temas no considerados por la historiografía tradicional.

Historia y Memoria fueron durante un tiempo un campo de batalla para los investigadores de la ciencia histórica. La primera asentada en la fuente escrita y la segunda en la oral compitieron por imponerse en la construcción de los hechos históricos. No fueron pocos los que caracterizaron por entonces a la Historia como un proceso intelectual objetivo y a la memoria como una actividad subjetiva y emocional, haciendo de este modo que esta última no se considerara adecuada en los círculos académicos oficiales. El historiador François Hartog ha sido uno de los críticos franceses más importantes -junto con Pierre Nora o Paul Ricoeur, entre otros- de esta postura que condena la Memoria al ámbito extraacadémico. Así, afirma en uno de sus trabajos que la memoria es un derecho, un deber, un arma, una alternativa a la historia que ha fallado, que ha muerto. Una historia de vencedores y no de víctimas, de olvidados, de dominados y de minorías. Una historia que no juzga ni condena, sino que humaniza y vuelve su mirada hacia la verdad (Hartog, 2009, p. 128).

Sin duda, Historia y Memoria están condenadas al entendimiento si se quiere construir una versión lo más aproximada posible a la verdad de nuestro pasado. La Memoria amplía el campo de la Historia, porque ayuda a reconstruir aquellos 
acontecimientos que han quedado oscurecidos por la escasez de fuentes. Pero, además, su importancia reside en que ofrece una historia desmitificada y crítica, renueva enfoques y abre nuevos campos de investigación (Ferrando, 2006, p. 19). Alejarse de los centros de poder para tomar el testimonio de la gente común no solo permite democratizar el discurso histórico, sino que nos acerca a la experiencia humana.

Recuperar la memoria histórica como base de la ciudadanía democrática es hoy en España un deber de justicia histórica, pues no solo sirve para afirmar nuestra democracia, sino que constituye una inversión de futuro, porque la identidad se construye en buena medida con el material de la memoria (Molinero, 2006).

Son varias las investigaciones que se presentan en nuestros días a las que se alude para referirse a la importancia de la formación del pensamiento histórico del alumnado de primaria y secundaria, pero no resultan ser frecuentes las investigaciones sobre la formación del profesorado para la Enseñanza de la Historia y del pensamiento histórico (Chávez y Pagès, 2017). Explican estos autores que para la formación de este pensamiento histórico se hace necesario establecer cuatro ejes: 1) la construcción de la conciencia histórico-temporal; 2) la comprensión de las formas de representación de la historia; 3) el desarrollo de la empatía histórica, como capacidad para imaginar lo que ocurrió en otros tiempos; y 4) el aprendizaje de la interpretación histórica, a través de la lectura, el tratamiento y contraste de fuentes históricas (pp. 75-76).

Una de las mejores técnicas que se presentan para ensamblar estos cuatro ejes es la narrativa. Las fuentes orales permiten alejarse de la memorización de hechos históricos y adentrarse en el conocimiento de vivencias únicas que humanizan esos acontecimientos (Soria, 2015).

\subsection{Potencialidades de la historia oral en el ámbito educativo}

Tradicionalmente se ha recurrido a la enseñanza de la historia en el sistema educativo a través de la fuente escrita. Con frecuencia, se han realizado otras actividades complementarias como el visionado de documentales, la visita a museos o la asistencia a charlas, como métodos innovadores para enseñar a los estudiantes el pasado, actividades residuales que no han favorecido la motivación del alumnado hacia la comprensión de este pasado ni su interés por la Historia.

Numerosas experiencias demuestran el valor de las fuentes orales como una de las formas más gratificantes para aprender historia (Maizkurrena, 2008; Benadiba y Plotinsky, 2008). Sin duda, su uso en el aula convierte al alumnado en testigo prioritario del relato del pasado y le aporta la posibilidad de acceder a una historia conocida, alejada de los grandes relatos históricos y asentada en la microhistoria.

Entre los beneficios más destacados de esta forma de enseñar la Historia en el aula toma especial interés la posibilidad que esta ofrece de que el alumnado tenga 
un contacto directo con el medio en el que vive. Relacionar los acontecimientos que ha visto y estudiado en las diferentes etapas del sistema educativo a través de los libros de texto, con la experiencia de personas cercanas, resulta un aspecto crucial para que aprenda la historia como una experiencia real y pueda establecer conexiones entre el pasado y el presente. Y es que, como afirma Benadiba (2015), las fuentes orales ayudan a cuestionar la idea de que "el pasado ya pasó». Con la recuperación de los testimonios orales se puede analizar cómo el pasado está presente en las prácticas cotidianas y cómo influye en la manera de pensar y de actuar en el presente (p. 92).

Es precisamente esta conexión entre pasado y presente la que posibilita humanizar la historia que contamos, al no basarla exclusivamente en hechos, datos estadísticos y fechas, sino al ser construida desde un contexto cercano al estudiante y a sus experiencias personales, un hecho que aviva su interés y motivación por el conocimiento pretérito (Rodríguez, Luque y Navas, 2014). Además, desarrollar proyectos de trabajo en el contexto local a través de un objetivo concreto de estudio resulta de gran interés para promover el debate y la colaboración de familiares, vecinos e instituciones locales, abriendo un espacio para el debate público y la recuperación del patrimonio histórico material e inmaterial.

Otro de los beneficios más importantes que se han destacado en el uso de fuentes orales en el aula es que a través de estas se ofrece la oportunidad de aproximar a los estudiantes hacia procesos de investigación. Una de las singularidades que brinda este tipo de fuente es que el estudiante interviene desde el primer momento en su creación, aportando una fuente histórica inédita. La entrevista realizada fuera del espacio ordinario de aprendizaje les hace entrar en contacto con personas que generalmente se encuentran al margen de la institución educativa y tienen una larga experiencia de vida, por tanto, les invita a plantearse algunos dilemas como la cuestión de la temporalidad, de la ordenación cronológica, de la sucesión, del cambio y de la complejidad del tiempo histórico (Ferrando, 2006, p. 118).

Acercar al estudiante a la historia de testigos vivos posibilita trascender los límites de la hegemonía cultural y penetrar en la subjetividad, en la experiencia individual y, en definitiva, en el ser humano. Es esa subjetividad, la que como Benadiba (2011) afirma, adquiere un papel fundamental para lograr que la Historia y las Ciencias Sociales puedan ser apropiadas por parte de los estudiantes de una manera significativa. Precisamente, esta subjetividad es la que parte de la verbalización de acontecimientos por parte de los entrevistados, así como la narración de sus proyectos, frustraciones, ilusiones y éxitos, en los que quedará patente lo individual y lo colectivo. Los estudiantes se apropiarán de la historia narrada concreta para entender el pasado desde la singularidad, la conexión con lo humano y la significación.

Además, Costa y Magalhaes (2001) detallan que el trabajo con fuentes orales para la formación de futuros docentes es muy importante, ya que contribuye a su capacitación en el propio conocimiento de la persona y le ofrece la posibilidad de 
construir un aprendizaje simbólico y significativo. La fuente oral se convierte así en un recurso importante no solo para que el estudiante compruebe cómo la memoria tiene una perspectiva individual, sino que esta no puede ser comprendida sin tener en cuenta el contexto social en el que se teje. Se ayuda de este modo a reflexionar sobre la compleja red de relaciones que se establecen entre lo individual y lo colectivo tan difícil de transmitir desde otro tipo de fuentes.

En este complejo tejido social otra de las potencialidades del uso de la fuente oral es que permite al alumnado conocer los testimonios de personas que han estado al margen de la historia. El contacto con colectivos excluidos, les estimula a reflexionar sobre algunos temas transversales como el lenguaje, el género o la exclusión social que favorecen la visión crítica hacia el pasado y el presente. Además, el contacto directo con la realidad investigada permite desarrollar una serie de sentimientos y emociones personales que ayudan a conocer la complejidad de las relaciones sociales primarias (Grana y Alonso, 2009).

En definitiva, la oralidad se presenta como un proceso potencialmente transformador para cambiar las formas de pensar, de ver y de ser, para fomentar la escucha activa y atenta al pasado, para desafiar los límites de lo estático, para penetrar en el mundo de lo cotidiano, para acercarse a grupos oprimidos por el sistema y, cómo no, para enseñar una Historia que deja a un lado los grandes acontecimientos históricos para dar voz al sentimiento humano.

\subsection{Proyectos de historia oral en el nivel universitario}

La tradición de la historia oral ligada a la docencia en el ámbito histórico-educativo cuenta con una amplia trayectoria en España. Son varias las experiencias que revelan el valor de esta fuente para la enseñanza de la historia y el conocimiento del pasado. Haciendo un estudio exploratorio a través de las temáticas que se han presentado hasta el momento, vemos cómo se han abordado a través de fuentes orales ejes temáticos como el género en el siglo xx (Grana y Alonso, 2009; Redondo, 2012), el franquismo (Robles y Grana, 2007; Benadiba y Plotinsky, 2008; Grana y Alonso, 2009; Grana, 2012; Ortega, 2012; Sonlleva, Sanz y Rabazas, 2018) o la Segunda República (Rabazas et al., 2018). Algunas de estas experiencias han sido llevadas a cabo en museos vinculados con el patrimonio histórico-educativo, mostrándose estos lugares como espacios destacados para el recuerdo y la memoria.

Dentro del ámbito universitario son varios los proyectos que han sido realizados con este tipo de fuentes. Así, a finales del siglo xx se encuentran algunas experiencias en forma de talleres (Hernández, Iglesias y Quintana, 1991). Unos años más tarde, ya iniciado el siglo XXI, vieron la luz, nuevas experiencias como la de Anadón (2006), en la Universidad Complutense de Madrid, que trataba de recuperar a través de fotografías y relatos orales la historia pasada; o la de Jiménez (2009) en la Universidad de Granada, con fines semejantes. A estas experiencias les siguieron 
algunos proyectos más ambiciosos como el de Cuesta (2009), vinculado con la recuperación de la memoria de la Guerra Civil; el de Ferrando (2006), relacionado con la inmigración catalana en el siglo xx.

Desde el año 2010 han surgido nuevos proyectos que, adaptándose a los nuevos tiempos, trabajan con fuentes orales y audiovisuales, como el realizado en la Universitat de Barcelona, bajo el nombre Habilitats i competències dels estudiants universitaris en la utilització de les fonts orals i audiovisuals de la història de l'educació contemporània. En él se parte de la reflexión sobre qué y cómo se enseña la Historia de la Educación, haciendo uso de las fuentes orales y audiovisuales y considerando al alumnado como parte activa del proceso educativo (Moreu, 2010). Por su parte, el profesor Pablo Álvarez Domínguez, de la Universidad de Sevilla, implantó el proyecto Producción y narración digital colaborativa entre estudiantes universitarios: Elaboración de vídeos didácticos y creativos mediante role playing, haciendo uso de los discursos narrativos e implicando, nuevamente, al alumnado como eje central de la educación en Historia.

Destacamos en este recorrido el caso de Ortega Castillo (2012), quien puso en marcha hace unos años un proyecto docente basado en la recuperación de historias de vida durante el franquismo con alumnado del Grado de Educación Infantil de la Universidad de Málaga. Para su consecución, se partía de dos bloques temáticos. El primero llevó por título La infancia de mis abuelos, y consistía en la aplicación de entrevistas no sistematizadas con los familiares del alumnado. El segundo bloque se basaba en aplicar la información que habían obtenido a través de las historias de vida al temario de la materia, constituida en torno a los ejes de espacio, contenido, maestros y alumnos.

En los últimos años, otros trabajos como el de Bilbao, Pérez y Ezkurdia (2014), para la recuperación de testimonios de maestros por parte de los docentes en formación; o el de Andreu (2017) sobre las relaciones entre la Historia y la identidad, marcan nuevas líneas de investigación. También, la obra de Martínez, García-Moris y García (2017), que recopila un importante número de experiencias con estudiantes de Magisterio -y algunas de ellas con fuentes orales y etnográficas- para la enseñanza de las Ciencias Sociales, resultan ser trabajos reseñables en este apartado de la investigación.

El análisis de las experiencias anteriormente mencionadas nos lleva a extraer dos conclusiones fundamentales. La primera de ellas es que no son abundantes los proyectos con fuentes orales en el ámbito universitario. Sí existen, en cambio, muchas más experiencias en la Educación Secundaria Obligatoria y el Bachillerato dentro de la asignatura de Historia, como la de Sarria (2008). Si bien se observa cómo tímidamente su uso va aumentando a lo largo de los años, aún nos encontramos ante una práctica poco usual en el aula universitaria. La segunda -que muestra una amplia conexión con la primera conclusión- es que la mayoría de las experiencias formativas presentadas se vinculan exclusivamente con una asignatura de los 
diferentes planes de estudio, un aspecto que impide que los estudiantes sean capaces de conocer las posibilidades interdisciplinares que ofrece el trabajo con este tipo de fuentes orales.

Sin duda, como afirma Benadiba (2007) y se ha puesto de relieve en multitud de trabajos, la enseñanza de la Historia en el aula resulta ser compleja, pero las fuentes orales nos ofrecen la oportunidad de analizar los procesos sociales y la vida de la gente común y ponerlos en debate con la macrohistoria, algo que muy pocas fuentes permiten hacer.

\section{ENSEÑAR LA HISTORIA DE LA EDUCACIÓN A TRAVÉS DE FUENTES ORALES. UN PROYECTO DE INNOVACIÓN DOCENTE}

En el curso académico 2016/2017 una decena de docentes de la Universidad de Valladolid detectamos cómo en los planes de estudio de Magisterio de Educación Infantil y Primaria de nuestra institución no existía ninguna asignatura concreta que enseñara a nuestros estudiantes la Historia de la Educación Española Contemporánea. Tras un análisis pormenorizado de las guías docentes de todas las asignaturas que componen dichas titulaciones, advertimos que este contenido se trabajaba en algunos de sus bloques de forma transversal o residual.

Al inicio del curso 2016, realizamos una encuesta piloto a más de ochenta estudiantes de Magisterio de la Facultad de Educación de Segovia, que cursaban sus estudios desde primero hasta cuarto curso de Grado. En dicha encuesta preguntábamos por algunos hitos relevantes de nuestra historia pasada vinculados con fechas conmemorativas, personajes relevantes, acontecimientos de la educación del siglo xx y algunas otras cuestiones ligadas con la pedagogía contemporánea. Esta encuesta nos permitió detectar las graves consecuencias que estaba teniendo en la formación de los futuros docentes, el tratamiento transversal de los temas vinculados con la Historia de la Educación Española Contemporánea y debatir sobre las repercusiones que estas carencias tendrían en sus trayectorias profesionales.

Los resultados obtenidos sirvieron de aval en septiembre de ese mismo año para presentar un Proyecto de Innovación Docente (PID) en la Universidad de Valladolid cuyos objetivos trataban de: a) Potenciar el uso de las fuentes orales y fotografías como recursos para la enseñanza de asignaturas con contenidos histórico-educativos en el Grado de Maestro; b) Introducir al alumnado en el campo de la investigación narrativa e iconográfica, a través de pequeños proyectos de investigación histórico-educativa que pusieran en juego estrategias democráticas y comprometidas; c) Conseguir que los futuros docentes construyeran una visión comprensiva del funcionamiento histórico de la escuela, a partir de la reflexión crítica sobre los cambios en la formas de educar a la infancia; d) Crear un grupo de 
trabajo multidisciplinar entre profesionales de distintas áreas que favoreciera una estructuración de la enseñanza universitaria más holística e integradora y fomentara el desarrollo de actividades de investigación con intereses compartidos; y e) Acercar los conocimientos producidos en la Universidad a la sociedad a través de actividades formativas que rescatasen la memoria histórico-educativa y recuperasen el patrimonio escolar.

Después de tres años de trabajo y bajo el nombre Memoria de la escuela contemporánea: fuentes orales, iconográficas y otros recursos pedagógicos para la formación docente, el Proyecto está teniendo su continuidad en el presente curso académico y ha sido calificado por el Área de Formación e Innovación Docente de la Universidad de Valladolid como Destacado, tomando como criterios positivos para esta valoración su coherencia, trayectoria, relevancia y carácter innovador.

EI PID se enmarca dentro de la línea estratégica propuesta por el Vicerrectorado para el curso 2018/2019, que toma a los estudiantes como eje central de la Universidad, siendo nuestra prioridad ofrecer la mejor formación posible a los futuros docentes para que puedan tener una carrera profesional exitosa, sustentando sus aprendizajes en una buena formación histórico-educativa.

El Proyecto también viene justificado por la necesidad de introducir metodologías docentes innovadoras en las clases teóricas y prácticas del ámbito universitario y la transformación del papel docente de transmisor de conocimientos a guía y orientador del aprendizaje, aspectos que van en consonancia con las directrices del Espacio Europeo de Educación Superior.

Nuestro objetivo prioritario es formar a los estudiantes del Grado en Maestro de la UVa en contenidos vinculados con la Historia de la Educación Contemporánea, a través de proyectos de trabajo - previamente programados por los miembros del PID para las diferentes asignaturas que participan en el mismo-, que utilizan el método de investigación biográfico-narrativo y la iconografía como fuentes primarias de conocimiento para profundizar en la educación pretérita. El trabajo con fuentes orales e iconográficas en el ámbito universitario supone una innovación educativa, porque, como apunta Fuertes (2015), este tipo de fuentes no han sido apenas utilizadas en este nivel y posibilitan al estudiante el acercamiento al conocimiento a través de una intervención activa. El uso de este tipo de herramientas convierte al estudiante en investigador y posibilita la adquisición de competencias y habilidades difíciles de conseguir por otros medios. Como ya hemos visto, estudios nacionales e internacionales avalan el valor de esta metodología para la formación universitaria y demandan su uso en la formación del profesorado.

Además, el PID cuenta actualmente con la participación de un grupo interdisciplinar de docentes de la Universidad de Valladolid, la Universidad Complutense de Madrid y la Universidad de Málaga, con una amplia experiencia en temas vinculados con la metodología biográfico-narrativa, la Historia de la Educación y la Innovación Educativa. Algunos de estos profesores y profesoras han sido reconocidos 
por su trayectoria excelente en acciones y proyectos ligados a la mejora docente y social. Esta participación no solo ha beneficiado a nuestros estudiantes, sino que también nos ha permitido consolidar una red de trabajo colaborativa entre el profesorado del Proyecto, que nos obliga a reflexionar sobre nuestra práctica en el aula, compartir materiales de trabajo y llevar nuestras experiencias a la práctica social, aspectos de gran interés para evitar el aislamiento profesional.

El trabajo con organismos locales y regionales, así como con otras instituciones universitarias, nos ha ofrecido también la posibilidad de realizar algunas experiencias sociales (Sonlleva, Sanz y Rabazas, 2018), que tratan de recuperar la memoria histórica del siglo xx y dar a conocer los conocimientos generados en la universidad a la sociedad, repercutiendo estas actividades en el contexto institucional.

Actualmente son más de 200 estudiantes los que han podido participar en esta propuesta innovadora desde diferentes asignaturas de sus planes de estudio ${ }^{2}$, mostrando el $90 \%$ de los mismos en las encuestas finales del Proyecto, un alto nivel de satisfacción con los aprendizajes adquiridos, la metodología utilizada y la formación recibida.

\section{EL PROYECTO «VIVIR LA INFANCIA EN TIEMPOS DE GUERRA»}

\subsection{Descripción, contexto y objetivos}

Dentro de la línea de actuación del Proyecto de Innovación Docente mencionado en el anterior apartado, durante el curso 2018/2019 se programó un proyecto en la Facultad de Educación de Segovia, que trataba de recuperar la historia local de la infancia durante el periodo de la Guerra Civil (1936-1939).

En dicho proyecto participaron las asignaturas de Educación para la Paz y la Igualdad, impartida en el primer cuatrimestre del primer curso del Programa de Estudios Conjunto de Grado en Educación Infantil y Grado en Educación Primaria y que tiene una carga de 6 créditos ECTS; y la asignatura Corrientes Pedagógicas de la Educación Infantil, impartida en el segundo cuatrimestre del primer curso de la Titulación de Grado en Educación Infantil, con una carga de 6 créditos ECTS.

La asignatura Educación para la Paz y la Igualdad cuenta entre sus contenidos con un bloque destinado a la enseñanza de la Educación para la Paz y los Derechos Humanos en la España contemporánea. Asimismo, la asignatura Corrientes Pedagógicas de la Educación Infantil trata en uno de sus bloques de dar a conocer cómo fue

2 Actualmente participan en el PID los Departamentos de Didáctica de las Ciencias Experimentales, Sociales y de la Matemática; Pedagogía; y Didáctica de la Expresión Musical, Plástica y Corporal, de la Facultad de Educación de Segovia. Además, colaboran docentes del Departamento de Estudios Educativos de la Universidad Complutense de Madrid y del Departamento de Organización Escolar de la Universidad de Málaga. 
la educación en España en el siglo XX. Estas conexiones entre los bloques de las dos asignaturas nos llevaron a programar un proyecto desde el que mostrar a nuestros estudiantes cómo en tiempos de guerra, la infancia se presenta como uno de los colectivos sociales más vulnerables.

Elegimos de este modo que nuestros estudiantes investigaran el periodo de la Guerra Civil Española, para mostrarles cómo en aquellos años los menores se vieron sometidos a la escasez de alimentos y las deficientes condiciones sanitarias, aspectos que desembocaron en un incremento de enfermedades y en el peor de los casos, la muerte. A esta terrible privación se unió un modelo educativo represor, que violó la libertad y la capacidad crítica de los más pequeños. Queríamos que a través de la propuesta los docentes en formación fueran conscientes de la necesidad de conocer nuestro pasado reciente para poder valorar la importancia de una educación que potenciara el diálogo, la paz y la igualdad de derechos y oportunidades.

Esta intención educativa nos llevó a plasmar cuatro objetivos fundamentales para nuestro proyecto, titulado Vivir la infancia en tiempos de guerra: 1) Conocer cómo influyó la guerra civil española en los menores segovianos; 2) Valorar el papel de la familia y la escuela durante el conflicto armado; 3 ) Reflexionar sobre la pérdida de derechos humanos y la indefensión que vive la infancia ante cualquier ofensiva; y 4) Analizar la evolución de la educación en España a lo largo del siglo XX.

\subsection{Diseño y secuenciación del proyecto}

A nivel metodológico, el proyecto se inserta en la perspectiva cualitativa y trata de recuperar testimonios orales de la guerra civil en la provincia de Segovia. Se trata de una metodología activa, participativa y cooperativa que pasa por un total de siete fases, que pasamos a describir a continuación. Esta propuesta toma en consideración algunos aspectos que señalaban Feliu y Hernández (2013) en su obra sobre cómo enseñar la Guerra Civil española a los estudiantes a partir de experiencias concretas y enmarcadas en un contexto local, fomentando un debate crítico entre los estudiantes que no se reduzca a entender este periodo a través de fechas, batallas y personajes.

\section{A) Elección del objeto de estudio}

El proyecto Vivir la infancia en tiempos de guerra fue considerado por el equipo docente de las asignaturas Educación para la Paz y la lgualdad y Corrientes Pedagógicas de la Educación Infantil de la Facultad de Educación de Segovia, tras la realización de un estudio exploratorio sobre publicaciones relacionadas con la educación en el periodo de la Guerra Civil Española (1936-1939). Dicho estudio inicial, llevado a cabo a través de las bases de datos de Web of Science, SCOPUS, TESEO, Dialnet e 
ISOC, trataba de recuperar los estudios nacionales e internacionales relacionados con el descriptor «educación y guerra civil española». Tras el análisis de los 686 estudios encontrados extrajimos tres conclusiones fundamentales: a) que la mayor parte de las investigaciones se centraban exclusivamente en la educación formal; b) que muchos de estos trabajos consideraban la educación durante el periodo de la guerra civil a nivel local o regional (las zonas que acumulan un mayor número de estudios son Cataluña, Mallorca, País Vasco, Valencia y León); y c) que la fuente oral no ha sido la más considerada para la recuperación de las experiencias educativas de esta etapa pretérita.

Estas conclusiones nos llevaron a iniciar un proyecto que tratara de dar a conocer a nuestros estudiantes, a través de fuentes orales, cómo había sido vivida por la infancia de la provincia de Segovia la educación entre 1936 y 1939. Decidimos trabajar en este periodo histórico no solo porque los bloques de las dos asignaturas nos invitaban a hacerlo, sino también porque nos ofrecía la posibilidad de encontrar testimonios directos de aquel drama humano y obtener otras fuentes primarias para indagar en la educación de estos años.

La ausencia de estudios previos sobre esta región española y sobre la consideración de la educación desde el ámbito formal y no formal fue clave para que pudiéramos presentar nuestra propuesta dentro del ámbito de la innovación educativa. Además, la temática se vinculaba específicamente con uno de los bloques de las dos asignaturas vinculadas al PID, aspecto que nos ayudó a poder trabajar la experiencia en nuestras clases durante un tiempo prolongado y a conectarla con otros contenidos del temario.

Otro hecho a destacar que nos llevó a la decisión de contextualizar el proyecto en la provincia de Segovia, es que un amplio porcentaje de los estudiantes matriculados en las dos asignaturas habían nacido y vivido sus experiencias vitales en dicha región, por lo que el proyecto les permitiría trabajar desde su contexto más cercano y recuperar los testimonios de personas allegadas, posibilitándonos de este modo el acceso a las fuentes orales. Cumplíamos de este modo con los criterios de interés, motivación, originalidad y utilidad, que como explica Emili Ferrando, son necesarios para elaborar cualquier trabajo de investigación con fuentes orales (Ferrando, 2006, p. 27).

Para programar el proyecto tuvimos en cuenta algunos otros aspectos que es necesario destacar. El primero de ellos, es que tuviera un grado de dificultad asumible para nuestros estudiantes. Para ello, consideramos la necesidad de plantear diversas fases en su desarrollo y actuar como acompañantes y guías de su aprendizaje durante la duración de la experiencia. Precisamente esta duración fue otro de los aspectos considerados. La contextualización cuatrimestral de las asignaturas nos obligaba a establecer unos periodos determinados para el desarrollo del proyecto. Así, creímos conveniente dedicar el periodo de un mes como el tiempo adecuado para poder llevar a cabo la experiencia. 
B) Aproximación al periodo histórico de la Guerra Civil Española (1936-1939)

Tras la concreción de las actuaciones iniciales por parte del profesorado, comenzamos con el trabajo en el aula. En una primera fase, ofrecimos a nuestros estudiantes un listado con algunas publicaciones que seleccionamos de las bases de datos consultadas, con el fin de poder documentarles en el periodo de la Guerra Civil Española. Como detalla Mendioroz-Lacambra (2016) capacitarles en la búsqueda y tratamiento de la información resulta imprescindible para conocer el estado de la cuestión del problema que están investigando y hacerles conscientes de la importancia de la lectura y la reflexión para iniciar cualquier proyecto de estas características.

Los estudios fueron leídos de forma individual, permitiendo al alumnado formarse en aspectos centrales y componentes históricos del tema escogido. Posteriormente, los textos fueron debatidos en pequeños grupos, con el fin de poder comentar con otros compañeros las conclusiones extraídas.

Después de la fase de lectura, invitamos a nuestros estudiantes en pequeños grupos a continuar su formación consultando fuentes hemerográficas, censos, fotografías y vídeos con el fin de que pudieran zambullirse en este periodo de la historia de España. Durante este periodo, el profesorado también colaboró proporcionándoles recortes de prensa local sobre noticias ocurridas en la provincia de Segovia en el periodo de la guerra civil, además de ofrecerles documentación recogida del Instituto Nacional de Estadística, manuales escolares de este periodo y otras fuentes primarias.

Tras el debate en pequeños grupos y la búsqueda de fuentes primarias, terminamos esta segunda fase con una discusión en asamblea con el grupo clase. Esta sesión permitió a los futuros docentes extraer algunas conclusiones. La primera de ellas fue darse cuenta de los usos y abusos políticos de la narración del pasado a través de los libros y de las fuentes estadísticas, un hecho que despertó una conciencia crítica entre nuestros estudiantes. La segunda de estas conclusiones es que percibieron cómo algunos sectores de la población (principalmente la infancia, el colectivo femenino y los sectores marginados) apenas se veían representados en las fuentes hemerográficas consultadas. Y una tercera conclusión es que verbalizaron cómo ellos mismos no estaban suficientemente formados en temas relacionados con la historia pasada, discutiendo sobre cómo el periodo de la Guerra Civil en la Educación Secundaria Obligatoria y el Bachillerato había sido tratado en los diferentes cursos de forma residual.

Estas conclusiones llevaron al alumnado a comprender cómo la historia estaba sometida a ciertos filtros que impedían tener una visión global y asentada en los pilares de la verdad sobre nuestro pasado, aspecto que favoreció su motivación e interés por continuar el proyecto e investigar sobre el periodo histórico marcado. 


\section{C) Formación metodológica}

La tercera fase tenía como objetivo formar a nuestros estudiantes en la creación de fuentes orales. Para ello, primero ofrecimos una sesión teórica para enseñar qué eran, su relación con la investigación histórica y los beneficios y limitaciones que nos ofrece esta forma de acercarnos al pasado.

En un momento posterior, tratamos de enseñar al alumnado cómo la herramienta más utilizada para la recuperación de testimonios es la entrevista e indagamos sobre sus usos. Con esta teoría inicial pretendíamos ofrecer cierta seguridad al profesorado en formación y facilitarle un decálogo de elementos clave para que esta parte de la investigación no quedara manchada por los errores comunes que suelen cometerse como entrevistador novel. Esta fase permitió a los futuros docentes familiarizarse con la metodología que iba a guiar la investigación de sus proyectos.

\section{D) Hipótesis de trabajo y redacción del cuestionario}

Avanzando en nuestro proyecto, la cuarta fase tenía como objetivo establecer las hipótesis de trabajo y redactar un cuestionario que les sirviera de guía durante las entrevistas.

Para la formulación de hipótesis, les pedimos que confeccionaran una lista sobre preguntas y posibles respuestas de los hechos ocurridos durante el periodo bélico a nivel local. Tras una sesión de debate de estas preguntas, los estudiantes llegaron a la conclusión de que algunas de ellas podían ser respondidas con los documentos que habían sido utilizados en la fase $B$, pero de otras se desconocía la respuesta exacta.

A partir de estas preguntas comenzamos a privilegiar aquellas más relacionadas con el foco del proyecto «experiencias infantiles vinculadas a la educación durante la guerra civil» y a excluir algunas otras que no resultaban importantes para la investigación. Para esta selección, les recordamos de nuevo que los objetivos del proyecto eran: 1) Conocer cómo influyó la guerra civil española en los menores segovianos; 2) Valorar el papel de la familia y la escuela durante el conflicto armado; 3) Reflexionar sobre la pérdida de derechos humanos y la indefensión que vive la infancia ante cualquier ofensiva; y 4) Analizar la evolución de la educación en España a lo largo del siglo $x x$.

La formulación de preguntas fue clave para distinguir posibles temas principales y secundarios de la investigación, así como para descubrir los apartados en los que queríamos dividir el cuestionario para responder al objetivo del proyecto. Finalmente, docentes y estudiantes elaboramos un cuestionario compuesto por 25 preguntas (Tabla 1). Las preguntas estaban ordenadas en cinco bloques de contenido-Recuerdos del contexto en el que se teje la vivencia personal; Descubrimiento del comienzo de la guerra civil; Vivencias en el contexto familiar; Experiencia escolar; Memoria y sentimientos tras el conflicto bélico-desde los cuales el alumnado pretendía conocer 
la repercusión de la Guerra Civil en la trayectoria vital de las personas que iban a ofrecer su testimonio y profundizar en la educación recibida en este periodo.

Decidimos que el tipo de entrevista más conveniente para este proyecto debía ser cerrada, semidirigida y centrada en las experiencias biográficas de la persona que decidiera aportar su testimonio, con el fin de que los estudiantes se sintieran seguros en su realización y ahondaran en los aspectos subjetivos de la vivencia de la persona entrevistada.

Tabla 1. Cuestionario «Vivir la infancia en tiempos de guerra»

\begin{tabular}{|c|c|}
\hline Bloques de contenido & Preguntas \\
\hline \multirow{5}{*}{$\begin{array}{l}\text { Recuerdos del } \\
\text { contexto en el que } \\
\text { se teje la vivencia } \\
\text { personal }\end{array}$} & $\begin{array}{l}\text { 1. ¿Cómo recuerdas el lugar en el que vivías cuando comenzó la Guerra } \\
\text { Civil? (habitantes, economía, tradiciones...) }\end{array}$ \\
\hline & 2. ¿Cómo era tu casa? \\
\hline & 3. ¿Qué recuerdas sobre tu familia? \\
\hline & 4. ¿Tus padres eran creyentes? ¿̇lban a misa? \\
\hline & 5. ¿Qué relaciones tenías con vecinos y amigos? \\
\hline \multirow{5}{*}{$\begin{array}{l}\text { Descubrimiento del } \\
\text { comienzo de la Guerra } \\
\text { Civil }\end{array}$} & 6. ¿Cómo te enteraste de que había empezado la guerra? \\
\hline & 7. ¿Qué recuerdos tienes de aquel día que comenzó la guerra? \\
\hline & 8. ¿Cambió tu vida en aquel periodo? \\
\hline & $\begin{array}{l}\text { 9. ¿Cuáles fueron tus sentimientos al conocer que había empezado la } \\
\text { guerra? }\end{array}$ \\
\hline & 10. ¿Alguien te explicó lo que suponía aquel conflicto? \\
\hline \multirow{5}{*}{$\begin{array}{l}\text { Vivencias en el } \\
\text { contexto familiar en } \\
\text { tiempo de guerra }\end{array}$} & 11. ¿Qué experiencias recuerdas junto a tu familia durante la guerra? \\
\hline & 12. ¿Perdiste a algún familiar en aquellos años? \\
\hline & 13. ¿Tu familia disponía de recursos alimenticios, higiénicos...? \\
\hline & $\begin{array}{l}\text { 14. ¿Participabas con tus padres en celebraciones religiosas? ¿y } \\
\text { patrióticas? }\end{array}$ \\
\hline & 15. ¿Qué actividades realizabas con tu familia en el tiempo de ocio? \\
\hline \multirow{5}{*}{ Experiencia escolar } & 16. ¿lbas a la escuela cuando empezó la guerra? ¿Cómo era tu escuela? \\
\hline & 17. ¿Cómo estaba distribuido el aula? \\
\hline & 18. ¿Qué materiales escolares solían utilizarse? \\
\hline & $\begin{array}{l}\text { 19. ¿Recuerdas las actividades que realizabais durante la jornada } \\
\text { escolar? }\end{array}$ \\
\hline & 20. ¿Cómo podrías describir a tu maestro/a? \\
\hline \multirow{5}{*}{$\begin{array}{l}\text { Memoria y } \\
\text { sentimientos tras el } \\
\text { conflicto }\end{array}$} & 21. ¿Qué recuerdos tienes del día que terminó la guerra? \\
\hline & 22. ¿Seguiste estudiando después de la guerra? \\
\hline & 23. ¿Cómo vivió tu familia el final del conflicto? \\
\hline & $\begin{array}{l}\text { 24. ¿Qué recuerdas de los poderes locales tras el fin de la guerra? } \\
\text { (Iglesia, Alcalde, Guardia Civil...) }\end{array}$ \\
\hline & $\begin{array}{l}\text { 25. ¿Cómo cambió tu vida aquel conflicto? ¿Qué sentimientos tienes al } \\
\text { recordarlo? }\end{array}$ \\
\hline
\end{tabular}


Para que el alumnado pudiera enmarcar la experiencia de la persona entrevistada, el profesorado elaboró una ficha biográfica que trataba de recoger datos personales del entrevistado como el nombre y los apellidos, la fecha y el lugar de nacimiento, el estado civil, los estudios realizados y la profesión, que debía ser cumplimentada en el momento previo a la realización del encuentro grabado.

E) Búsqueda de fuentes

La quinta fase del proyecto consistió en la búsqueda de personas que hubieran nacido en la provincia de Segovia antes de 1933 y estuvieran en plenas condiciones para poder narrar su experiencia.

En esta fase pedimos a los estudiantes que se agruparan en parejas, de tal forma que aquellos que no tuvieran acceso a los testimonios de personas segovianas con las características mencionadas pudieran trabajar con otros compañeros que sí lo tuvieran.

Identificados 21 participantes en cada uno de los grupos-clase, nacidos en la capital de Segovia y los pueblos de la provincia, pedimos a las parejas que tuvieran un primer contacto con la persona que iba a ceder su testimonio. Esta reunión debía servir para comunicar los objetivos del proyecto, explicar con qué fines iba a ser utilizado el testimonio, crear un ambiente de confianza y proponer una fecha para la realización de la entrevista.

Además, en esta fase debatimos con los estudiantes sobre los códigos éticos que íbamos a seguir en la investigación, siguiendo las propuestas de Kirsch (1999) y Sandín (2003). Los acuerdos a los que llegamos y que debían tener en cuenta en todas las entrevistas fueron: a) Obtener consentimiento para grabar las entrevistas y transcribirlas posteriormente con fines puramente investigadores; b) Proteger la confidencialidad de las personas participantes, evitando añadir al informe final cualquier dato personal que no fuera objeto del estudio; c) Asegurar que los participantes no se vieran afectados por su colaboración en la investigación, garantizando su bienestar y reputación; y d) Permitir que la participación de los participantes en el estudio fuera voluntaria, pudiendo retirarse de la misma en cualquier momento sin ninguna repercusión negativa.

Del mismo modo, indicamos al alumnado algunas pautas para la realización de la entrevista cuando aspectos como: el espacio en el que se iba a realizar, el buen funcionamiento de las grabadoras, el correcto tratamiento a la persona que iba a ceder su testimonio, la empatía, el cuidado del lenguaje, etc.

F) Elaboración del trabajo final

La penúltima fase de la investigación tuvo tres actividades claramente diferenciadas: la transcripción de la entrevista, la interpretación de los datos y la elaboración de las conclusiones. 
Para la transcripción de la entrevista pedimos a los futuros docentes que reprodujeran en un documento las palabras textuales de los narradores, pero además que indicaran todos aquellos aspectos no verbales que hubieran percibido durante el encuentro grabado (silencios, gestos, movimientos...). Esta transcripción literal nos iba a permitir en una fase posterior enseñar a nuestros estudiantes los giros que se producen en el discurso y el poder de la comunicación no verbal para expresar sentimientos y emociones.

Tras esta primera actividad se procedió a hacer una interpretación de la información recogida en el aula. Para ello, pedimos que cada pareja ordenara los datos recogidos en un esquema desde el cual se pudiera comprobar si las respuestas obtenidas en los testimonios nos permitían dar contestación a los interrogantes que nos planteábamos al comienzo del estudio.

Esta organización de la información también nos permitió facilitar a los estudiantes la elaboración de algunas conclusiones por cada bloque de contenido y formular nuevos interrogantes que podríamos tener en cuenta en estudios posteriores con otros grupos de estudiantes.

G) Reflexión final

El proyecto Vivir la infancia en tiempos de guerra concluyó con un debate final en el aula en el que cada pareja mostraba al resto de la clase las conclusiones a las que había llegado a través de su estudio. La verbalización de las experiencias llevó a los estudiantes a establecer algunas conexiones entre lo descubierto a través de los testimonios y lo aprendido en las primeras fases de investigación con fuentes escritas, iconográficas y estadísticas.

En la discusión de los datos, también aparecieron algunas voces que mostraron la crítica a las fuentes orales, un tema que era para nosotros de gran interés, pues nos permitía saber si el alumnado era capaz de establecer una crítica ante cualquier fuente histórica y poder debatir sobre algunos aspectos de la fuente oral como la fiabilidad, la autenticidad, los problemas del recuerdo, el olvido y la memoria o las conexiones entre el pasado y el presente.

Esta sesión de debate también fue positiva para que el proyecto de historia oral no quedara aislado de los contenidos trabajados en las diferentes asignaturas. Por ello, en la asignatura de Educación para la Paz y la lgualdad, debatimos sobre las conexiones existentes entre la experiencia y la conculcación de los derechos humanos en aquel periodo de nuestra historia reciente, el tratamiento del género y la influencia de los conflictos armados para los grupos sociales más vulnerables, temas que coinciden con tres bloques de la asignatura. En el caso de la materia Corrientes Pedagógicas de la Educación Infantil, aprovechamos la sesión para finalizar haciendo mención a la influencia de la familia en el cuidado, la protección y la transmisión de modelos para la infancia; el papel de la escuela 
como agente de socialización, las repercusiones de la guerra civil en la educación española del siglo xx y la comparación de las experiencias vividas por estos menores españoles con otros europeos que vivieron su infancia en el marco de la Segunda Guerra Mundial.

La última fase culminó con la entrega de un cuestionario anónimo de cinco preguntas vinculadas con los objetivos de la investigación, que trataban de valorar la opinión de los estudiantes en relación a la propuesta. Además, cada participante debía entregar un informe cualitativo individual en el que concretara el porqué de sus respuestas.

\section{APUNTES METODOLÓGICOS}

\subsection{Fases de la investigación}

La investigación que presentamos se asienta en una metodología mixta. Son cuatro las fases por las que ha pasado el estudio. La primera de ellas se basó en la caracterización de los participantes de la muestra y en la elaboración de un cuestionario que atendiera a los objetivos del Proyecto «Vivir la infancia en tiempos de guerra». Posteriormente, tras la realización del Proyecto, se administraron los cuestionarios por el equipo de investigación para el alumnado matriculado en las asignaturas Educación para la Paz y la lgualdad y Corrientes Pedagógicas de la Educación Infantil, de la Facultad de Educación de Segovia. Además, en esta fase, se pidió a los participantes la elaboración de un informe cualitativo en el que además de explicar el porqué de las respuestas de cada uno de los ítems, dieran a conocer los sentimientos que les había provocado conocer de primera mano el testimonio de un niño o una niña que vivió durante su infancia la Guerra Civil y las conclusiones que extraía del proyecto para su aprendizaje. Tras la recogida de datos, se procedió a su categorización bajo los objetivos del presente artículo. Finalmente, los datos fueron puestos en discusión con otros estudios previos y se redactó el informe de resultados.

\subsection{Participantes}

En el proyecto participaron 83 estudiantes de la Facultad de Educación de Segovia matriculados en el curso 2018/2019 en las asignaturas Educación para la Paz y la Igualdad del primer curso del Programa de Estudios Conjunto de Grado en Educación Infantil y Grado en Educación Primaria y Corrientes Pedagógicas de la Educación Infantil del primer curso de la Titulación de Grado en Educación Infantil.

En la asignatura Educación para la Paz y la Igualdad llevaron a cabo la experiencia 7 hombres y 35 mujeres. De ellos, 21 proceden de la provincia de Segovia y el 
resto de Guadalajara (1); Mallorca (1); Madrid (6); Almería (1); Valladolid (3); Pontevedra (1); Cáceres (1); Cantabria (1); León (1); Albacete (1) y Toledo (1).

En la asignatura Corrientes Pedagógicas de la Educación Infantil participaron 41 estudiantes, de los cuales 38 son mujeres y 3 son hombres. De entre este grupo de estudiantes 17 proceden de la provincia de Segovia y el resto de Palencia (1); Madrid (12); Alicante (1); Burgos (2); Soria (1); Valladolid (3); La Rioja (1); y Orense (2).

La edad media de los dos grupos de participantes es de 20 años.

\subsection{Instrumentos para la recogida de datos}

Explicábamos en apartados previos que la recogida de datos se realizó a través de dos instrumentos: un cuestionario y un informe.

Con relación al cuestionario, para conocer la valoración que los estudiantes hacían de la experiencia vivida en el proyecto se formularon cinco ítems correspondientes con los objetivos del proyecto (Tabla 2). Para la respuesta a cada uno de los ítems se utilizó una escala tipo Likert de cinco puntos donde 0 es «totalmente en desacuerdo" y 5 es "totalmente de acuerdo».

Tabla 2. Cuestionario del Proyecto "Vivir la infancia en tiempos de guerra»

\begin{tabular}{|c|c|c|c|c|c|c|}
\hline Ítems & 0 & 1 & 2 & 3 & 4 & 5 \\
\hline $\begin{array}{l}\text { 1. El proyecto me ha ayudado a conocer la influencia de la Guerra } \\
\text { Civil en la infancia }\end{array}$ & & & & & & \\
\hline $\begin{array}{l}\text { 2. El proyecto me ha permitido valorar la influencia de la familia en la } \\
\text { educación de la infancia durante el periodo de la Guerra Civil }\end{array}$ & & & & & & \\
\hline $\begin{array}{l}\text { 3. El proyecto ha sido relevante para descubrir el influjo de la } \\
\text { educación formal en la identidad de la infancia durante la Guerra Civil }\end{array}$ & & & & & & \\
\hline $\begin{array}{l}\text { 4. El proyecto me ha ayudado a reflexionar sobre la pérdida de } \\
\text { derechos y la indefensión que vive la infancia ante una ofensiva }\end{array}$ & & & & & & \\
\hline $\begin{array}{l}\text { 5. El proyecto ha favorecido mi aprendizaje en el conocimiento de la } \\
\text { educación española del siglo xx }\end{array}$ & & & & & & \\
\hline
\end{tabular}

Fuente: Elaboración propia.

Para completar los datos cuantitativos, se pidió a cada estudiante que realizase un informe individual cualitativo, en el que explicaran el porqué de cada una de las respuestas ofrecidas a estos cinco ítems y, además, que escribieran una reflexión sobre la práctica realizada. En ella, pedíamos que cada persona expresara sus aprendizajes durante el desarrollo del proyecto y los sentimientos que les había suscitado el conocer a través de fuentes orales la historia de un periodo tan convulso como el que vivió España a finales de los años treinta del siglo Xx. Además, cada participante debía terminar este informe con una conclusión sobre lo aprendido y explicar para qué les servía este conocimiento como futuros maestros. 


\subsection{Análisis de los datos}

Los datos cuantitativos fueron sometidos a un análisis a través del programa estadístico SPSS 20.0 desde las variables sexo y grupos. Junto al análisis descriptivo simple de estas variables, realizamos un análisis general de las respuestas ofrecidas por los estudiantes en cada uno de los ítems propuestos en el cuestionario.

Para el análisis de datos cualitativos se trabajó con el programa Atlas.ti. Para este análisis, primero se leyeron los 83 informes individuales redactados por los estudiantes y se procedió a realizar un mapeo general de sus respuestas. Después se llevó a cabo una categorización simple, seleccionando los extractos relevantes de cada una de las respuestas cualitativas de los cinco ítems del cuestionario, así como las respuestas ofrecidas en la última pregunta del informe, ordenadas bajo tres categorías: aprendizajes de la práctica; sentimientos provocados tras la realización de la entrevista; y relaciones del proyecto con su el futuro profesional de los maestros en formación.

Una vez realizados los dos análisis, se pusieron en debate los datos cuantitativos y cualitativos para la realización del informe de resultados. En el mismo, se presentan los más relevantes de cada una de las categorías mencionadas anteriormente. A los datos analizados se ha unido la discusión de los resultados con los obtenidos en otras investigaciones similares, con el objetivo de potenciar el estudio.

Para la presentación de resultados, además de los gráficos de sectores que muestran las respuestas a cada pregunta del cuestionario, se han escogido algunos extractos de texto de los informes de los estudiantes con el objetivo de que el lector pueda conocer directamente desde la voz de los participantes el significado del proyecto y los aprendizajes obtenidos en el mismo. Las citas literales están acompañadas del sexo del estudiante y la asignatura desde la que ha realizado el proyecto. Para el sexo utilizamos las siglas H (hombres) y M (mujeres). Para la categorización por asignaturas nos servimos de las siglas EPI (Educación para la Paz y la Igualdad) y CPEI (Corrientes Pedagógicas de la Educación Infantil).

Los resultados se presentan discutidos bajo dos categorías de análisis generales, que se corresponden con los dos objetivos que nos marcábamos al inicio del artículo: 1) Conocer la influencia del proyecto en el conocimiento de los estudiantes sobre la vida y la educación en el periodo de la Guerra Civil española; y 2) Analizar la visión general de los estudiantes en la temática y los aprendizajes de la práctica realizada como profesionales del Magisterio. Dentro de estas dos grandes categorías de análisis se integran otras subcategorías que permiten profundizar en los datos analizados. 


\section{RESULTADOS}

Para valorar el impacto de la experiencia en la formación del alumnado hemos analizado en conjunto el cuestionario final del proyecto realizado y el informe realizado por cada uno de los ochenta y tres estudiantes. Pasamos a mostrar los resultados obtenidos de acuerdo con los objetivos del artículo.

6.1. Influencia del proyecto en el conocimiento de los estudiantes sobre la vida y la educación en el periodo de la Guerra Civil española

\subsubsection{Conocimiento de las repercusiones de la Guerra Civil en el colectivo infantil}

De acuerdo con los datos recogidos en el cuestionario de los estudiantes, más de un $98 \%$ del alumnado afirma estar de acuerdo (22,9\%) o muy de acuerdo $(75,9 \%)$ en que el proyecto "Vivir la infancia en tiempos de guerra» les ha servido para tener un conocimiento general sobre la influencia de la Guerra Civil Española en el colectivo infantil segoviano. Solo un estudiante no muestra opinión al respecto, cómo podemos ver en el siguiente gráfico:

Gráfico 1. Respuestas de los estudiantes al ítem 1 del cuestionario de valoración del proyecto

1. El proyecto me ha ayudado a conocer la influencia de la Guerra Civil en el colectivo infantil

m Totalmente de acuerdo $=$ De acuerdo $=$ Ni de acuerdo ni en desacuerdo $\mid$ En desacuerdo $=$ Totalmente en desacuerdo

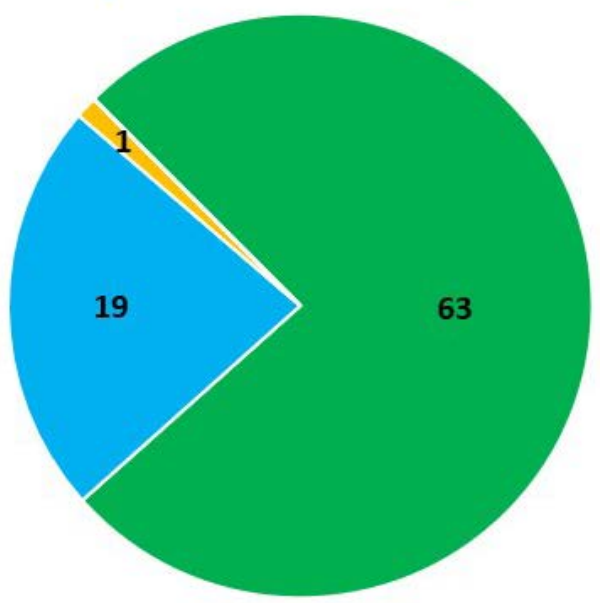

Si nos fijamos en las respuestas ofrecidas atendiendo a la variable sexo, la media de las mujeres $(4,80)$ es superior a la de los hombres $(4,40)$. Los sentimientos de las mujeres hacia el colectivo infantil y las vivencias que tuvieron durante el periodo bélico les hacen ser más sensibles hacia esta problemática. 
Los niños cuando son pequeños solo se deberían preocupar de jugar y de vivir su infancia con felicidad, y la realidad es que a todos estos niños que les tocó vivir esta tragedia les robaron toda su infancia y ya no la van a poder recuperar (Informe, M, EPI).

La asignatura también parece ser ilustrativa de las respuestas ofrecidas por los estudiantes. En Educación para la Paz y la Igualdad, del Programa de Estudios Conjunto de Grado en Educación Infantil y Grado en Educación Primaria, la media de las respuestas recogidas $(4,88)$ es superior a la de Corrientes Pedagógicas de la Educación Infantil $(4,63)$, del Grado En Educación Infantil. En ambos grupos, uno de los aspectos que más llamó la atención de los estudiantes fue cómo queda marcado en el recuerdo de la infancia, la guerra, el hambre, la muerte y la falta de recursos.

Cuando comentamos las entrevistas clase me di cuenta de que lo que nos había contado la persona que entrevistamos se repetía una y otra vez en los testimonios. Todos esos menores habían vivido el hambre, habían sufrido la muerte de familiares y conocidos, habían vivido su infancia en la más completa miseria... Aquello que a veces habíamos visto en las películas era real (Informe, M, CPEI).

La experiencia les sirve para tomar conciencia sobre cómo ciertos contenidos históricos han sido obviados a lo largo de su escolarización y la práctica les hace despertar una conciencia crítica ante los usos y abusos políticos del pasado.

Al principio del proyecto te das cuenta de que algunos colectivos no aparecen representados en las gráficas que nos trajo la profesora, ni en los periódicos y que apenas hay documentación sobre ello. Cuando hicimos las entrevistas y debatimos en grupos ya vimos que esa historia de la infancia nadie de clase la conocía. Sabíamos fechas, conocíamos personajes históricos, pero desconocíamos las repercusiones de aquella batalla (Informe, M, CPEI).

Como explican Feliu y Hernández (2013), el uso de las fuentes orales permite profundizar en el aprendizaje de una serie de conocimientos que no quedan reflejados en los libros de texto ni tampoco en los estudios a través de fuentes escritas. Por ello, los estudiantes que realizan este tipo de proyectos desarrollan una mayor sensibilización hacia las problemáticas sociales y hacia algunos aspectos propios de la cotidianidad que hasta el momento desconocían cuando pensaban en la Guerra Civil.

\subsubsection{Valoración sobre la influencia de la familia en la educación de la infancia}

En relación con las respuestas obtenidas en el cuestionario sobre el segundo ítem, que trataba de evaluar si a través del proyecto el estudiante había podido conocer la influencia de la familia en la educación de la infancia durante la Guerra 
Civil, más del $97 \%$ expresa una opinión positiva al respecto. Dos estudiantes no se posicionan ante este ítem, como se detalla en el gráfico que mostramos a continuación:

Gráfico 2. Respuestas de los estudiantes al ítem 2 del cuestionario de valoración del proyecto

2. El proyecto me ha permitido valorar la influencia de la familia en la educación de la infancia durante la Guerra Civil

- Totalmente de acuerdo $=$ De acuerdo $=$ Ni de acuerdo ni en desacuerdo $=$ En desacuerdo $=$ Totalmente en desacuerdo

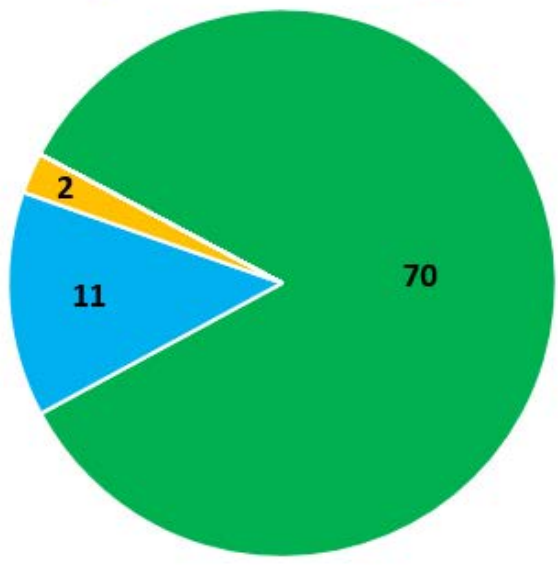

Atendiendo a la variable "sexo», la media de las respuestas ofrecidas por los hombres $(4,30)$ es inferior a la de las mujeres $(4,89)$. Ellas muestran en sus respuestas cualitativas cómo las madres constituyeron en aquel periodo un ejemplo de entrega y abnegación hacia la infancia.

En la entrevista de María hemos visto como ella recurre constantemente al recuerdo a su madre y la describe como una mujer buena, que se quitaba de comer para dárselo a sus hijos. Ella misma empezó a hacer lo mismo durante la posguerra, cuando sus hermanos pequeños pasaban hambre. Esto nos enseña cómo se reproducen los mismos comportamientos que la familia transmite en la infancia (Informe, M, CPEI).

El proyecto les hace ser conscientes de cómo en la mayoría de las familias se seguía un modelo de educación patriarcal-popular, caracterizado por la inculcación del principio de autoridad, representado en la figura paterna; en el que la madre se convertía en el refugio emocional de los menores y donde los niños eran sometidos a la norma. Además, ellas destacan desde la voz de los testigos vivos del conflicto, la pérdida de derechos a la que se vieron abocadas las mujeres desde el comienzo de la guerra y las diferencias en la educación de género transmitidas en el contexto familiar. 
Inmaculada nos contó que muchas veces a ella no le dejaban salir a la calle con sus amigas porque tenía que trabajar, mientras que su hermano sí podía hacerlo. Estaba obligada a hacer lo que le mandasen. $Y$ a pesar de no haber vivido la guerra de la peor manera, no tenía opinión propia con respecto a algunos temas (Informe, M, EPI).

En el caso de los estudiantes, al tratar esta problemática, se recurre con mayor frecuencia a la importancia de las enseñanzas familiares para aquellos menores que no pudieron asistir a la escuela y no tanto a los sacrificios familiares de los progenitores, especialmente de la madre, para proteger a los menores del hambre y la escasez.

La mayoría de las entrevistas dejan ver cómo la familia fue muy importante para educar a la infancia de estos años. Muchas de las personas entrevistadas no habían podido ir a la escuela y aprendieron todo lo que saben hoy de sus propios padres y de sus familiares (Informe, $\mathrm{H}, \mathrm{CPEI}$ ).

Estas respuestas nos llevan a pensar indudablemente en cómo el género marca el foco desde el que entender los acontecimientos del pasado y las formas de educar a la infancia a través de la familia. Estudios recientes, como el de Martínez y Ramírez (2017), nos invitan a formar al profesorado desde una mirada feminista que deconstruya los mandatos de género heteronormativos y elimine los roles y estereotipos de género, para que no sean transmitidos en el aula, una tarea sencilla, cuando se parte de los propios prejuicios que muestran los estudiantes. Las mismas autoras señalan que una buena forma de educar al profesorado bajo las claves de la des-patriarcalización consiste precisamente en dar voz a colectivos silenciados, como las mujeres y las personas sometidas tradicionalmente al silenciamiento de sus experiencias.

Si nos fijamos en la asignatura en la que fue impartida el proyecto, las medias son muy similares. En Educación para la Paz y la lgualdad la media es de 4,88 puntos mientras en Corrientes Pedagógicas de la Educación Infantil la media es de 4,75 puntos. Las repuestas ofrecidas en los informes por ambos grupos muestran cómo los estudiantes consideran a la familia como uno de los agentes de socialización más importantes para la educación de los menores de aquel periodo.

\subsubsection{Influencia de la escuela en la identidad de la infancia durante la Guerra Civil}

El tercer ítem del cuestionario pretendía conocer en qué grado los estudiantes habían percibido que el proyecto les había permitido descubrir el influjo de la escuela en la creación de la identidad de los niños y niñas que asistieron durante el periodo de la Guerra Civil a las aulas españolas. En este caso, el $100 \%$ de los estudiantes mostraron estar de acuerdo $(10,8 \%)$ o muy de acuerdo $(89,2 \%)$ con las bondades del proyecto para tal fin, como mostramos en el gráfico siguiente: 
Gráfico 3. Respuestas de los estudiantes al ítem 3 del cuestionario de valoración del proyecto

3. El proyecto ha sido relevante para descubrir el influjo de la educación formal en la identidad de la infancia durante la Guerra Civil

- Totalmente de acuerdo $=$ De acuerdo $=$ Ni de acuerdo ni en desacuerdo $=$ En desacuerdo $=$ Totalmente en desacuerdo

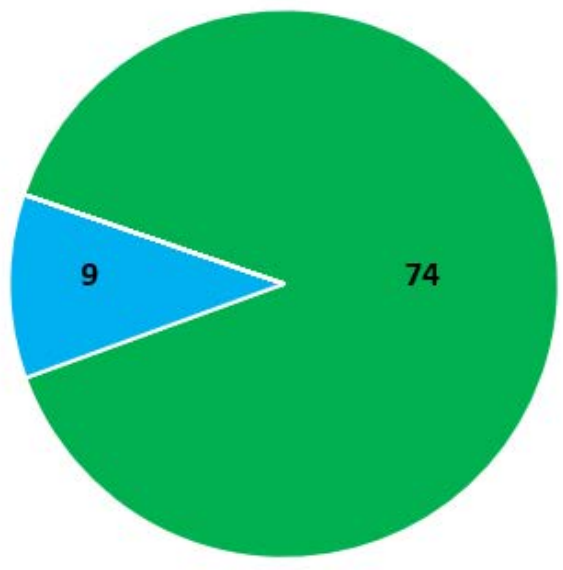

Desde la variable sexo, nuevamente la media de las respuestas ofrecidas por los participantes masculinos $(4,70)$ es inferior a la de las mujeres $(4,91)$. A través del informe se puede ver cómo las mujeres perciben en mayor grado la falta de materiales y recursos que tenían las escuelas segovianas del momento, un aspecto que despierta en ellas cierto sentimiento de tristeza al ver las privaciones a las que la infancia estuvo sometida.

Cuando nos contó que en su escuela no tenían juguetes, ni cuentos, ni ningún material sentí tristeza. Todos los niños de la clase tenían que compartir las cartillas y las pinturas que les dejaba la maestra, porque allí no había nada y las familias tampoco tenían dinero para comprarlo. Pienso en esa experiencia y creo que marcaría a cualquiera (Informe, M, EPI).

Ellos destacan en mayor grado la escasa experiencia educativa que vivieron las personas entrevistadas y la importancia que tiene la educación para la vida de las personas, un aspecto que les permite valorar su papel como docentes y que también aparece reflejado en otras investigaciones como las de Grana y Alonso (2009).

Ahora vemos lo difícil que era estudiar en esa época y que solo unos pocos privilegiados podían hacerlo, con lo que me ayuda a tener aún más ganas de seguir mi camino (Informe, H, CPEI). 
Atendiendo a la asignatura, aunque la diferencia de medias no es significativa, se observa que, en la materia de Educación para la Paz y la Igualdad, de la doble titulación de Grado en Educación Infantil y Primaria, la media $(4,92)$ es superior a la de Corrientes Pedagógicas de la Educación Infantil, de la titulación del Grado en Infantil (4,85). Los datos cualitativos de ambos grupos demuestran cómo los estudiantes perciben, por el tipo de estudios que están realizando, que uno de los agentes más influyentes para la educación de la infancia, durante el periodo de la Guerra Civil, fue el maestro. Sus prácticas en el aula les ayudan a conocer la importancia de este agente para la transmisión de la cultura entre los menores.

La maestra tuvo un papel protagonista. Como nos contaba la persona entrevistada fue ella la que les enseñó a leer y a no tener miedo de lo que estaba pasando. La maestra no faltaba nunca a clase y cuando se escuchaban a los aviones se ponía a cantar con las niñas, para que no les prestasen atención. Para mí tiene un mérito destacable (Informe, $\mathrm{M}, \mathrm{CPEI})$.

Estudios como el de Bilbao, Pérez y Ezkurdia (2014), en el que desde la asignatura Trabajo Fin de Grado de la titulación de Magisterio recuperan las historias de vida de maestras vascas, se percibe, igual que en nuestra investigación, cómo el trabajo del alumnado con fuentes orales les ayuda no solo a recuperar la memoria pasada, sino también a dar valor a la propia profesión docente. Las autoras de la investigación explican en su trabajo que esta es una asignatura pendiente tanto en la formación inicial como en la continua del profesorado, pues solo conociendo nuestra historia como docentes, podremos resituar nuestras prácticas y dignificar la profesión del Magisterio.

\subsubsection{Importancia del proyecto para la comprensión de la pérdida de derechos e} indefensión de la infancia ante una ofensiva

En relación con los datos recogidos en el cuestionario sobre la consideración del alumnado respecto a si el proyecto les había ayudado a reflexionar sobre la pérdida de derechos humanos que vive la infancia ante una ofensiva y la indefensión que sufre este colectivo, descubrimos que el $100 \%$ de los estudiantes dicen estar de acuerdo $(9,6 \%)$ o muy de acuerdo $(90,4 \%)$ con los resultados del proyecto para este fin. El gráfico siguiente representa sus respuestas: 
Gráfico 4. Respuestas de los estudiantes al ítem 4 del cuestionario de valoración del proyecto

4. El proyecto ha posibilitado reflexionar sobre la pérdida de derechos humanos y la indefensión que vive la infancia ante una ofensiva

- Totalmente de acuerdo $=$ De acuerdo $=$ Ni de acuerdo ni en desacuerdo $=$ En desacuerdo $=$ Totalmente en desacuerdo

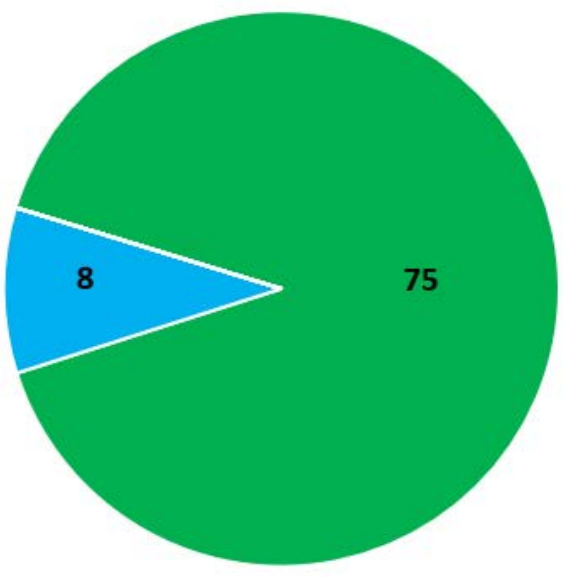

Atendiendo a la variable sexo, comprobamos que la media de las respuestas ofrecidas por las mujeres antes este ítem $(4,91)$ es superior a la de los hombres $(4,80)$. A ambos sexos, lo que más les llama la atención es cómo las personas entrevistadas, a pesar del paso del tiempo y su corta edad al comenzar el conflicto, recuerdan nítidamente el día que comenzó la guerra y sus experiencias en aquel periodo.

Me ha llamado mucho la atención cómo eran capaces de vivir en unas condiciones infrahumanas, comiendo lo mínimo y, sobre todo, cómo se normalizaba el tener que esconderse cuando oían un avión que se aproximaba (Informe, M, EPI).

Además, el contacto directo con los relatos les hace expresar ciertos aprendizajes interesantes en relación a los silencios que se presentan en los libros de texto hacia algunos temas del pasado.

Esto es algo que los libros de historia no muestran, ya que se centran en números, fases y batallas dejando de lado el componente más importante de una guerra, el humano. Es importante conocer esa evolución y componente político, sin duda, pero no podemos dejar de lado esas historias de "la gente de a pie», del pueblo, que son los que sacan adelante el país y los verdaderos protagonistas. Creo que debemos concienciarnos de la importancia de esa intrahistoria que es, al menos desde mi punto de vista, la base y la cima de lo que comúnmente llamamos Historia (Informe, H, EPI). 
González (2015) explica que los libros de texto contienen valores, ideas y conocimientos influenciados por diferentes elementos políticos y sociales que se espera sean abrazados y legitimados por los estudiantes. En el caso de la Guerra Civil, la investigación de este autor y la de otros como Boyd (2000; 2006), deja claro cómo aún en nuestros días, esta parte de la Historia de España sigue sometida a la censura de algunos contenidos sociales y se centra en el conflicto político. Los estudiantes dan cuenta de esta realidad y además la critican, un aspecto que nos permite anunciar que ha despertado en ellos una mirada crítica no solo ante los acontecimientos de aquel periodo, sino también hacia ciertos materiales e instrumentos escolares que sirven de guía para enseñar la Historia en la escuela.

Si nos fijamos en la media de los grupos por asignatura, los matriculados en Corrientes Pedagógicas de la Educación Infantil, del Grado de Educación Infantil tienen una media de respuesta inferior $(4,87)$ a la de las personas que cursan Educación para la Paz y la lgualdad, de la doble titulación de Grado en Infantil y Primaria $(4,92)$. En esta última asignatura, precisamente, uno de los bloques de contenido trata sobre los Derechos Humanos y se había impartido antes de llevar a cabo al proyecto, por ello creemos que los participantes encuentran en la experiencia una mayor vinculación con este ítem.

Lo aprendido en esta entrevista me ha hecho darme cuenta de que no existía ningún derecho humano. Podríamos decir que al niño se le vulneraban todos los derechos, hasta el de la educación ya que la mayoría tuvieron que dejar el colegio para ponerse a trabajar (...). Sin duda, la guerra cambió sus vidas para siempre (Informe, M, EPI).

A estos últimos alumnos, además, el proyecto les hace presentar una opinión crítica ante otras situaciones semejantes que vivimos en nuestros días, en las que la infancia sufre las consecuencias de un conflicto armado. Sus informes dan cuenta de cómo antes de llevar a cabo la experiencia del proyecto, se mantenían indiferentes ante estas problemáticas y tras él despiertan una mirada crítica.

Ahora miro la televisión y me doy cuenta de cómo los niños refugiados y todos los que están viviendo la guerra en nuestros días sufren los mismos problemas que las personas que entrevistamos. Antes lo veía como algo lejano, pero ahora siento que podemos hacer más de lo que estamos haciendo (Informe, M, EPI).

Los sentimientos de los estudiantes al conocer los testimonios de este recuerdo vivo de la guerra les hace reflexionar sobre las consecuencias que tiene esta vivencia para la trayectoria vital de los menores que la sufren.

Quizá uno de los aspectos importantes y que mejorarían los aprendizajes de los estudiantes para comprender cómo fueron las experiencias de los menores du- 
rante la guerra sería ampliar el proyecto en la línea que muestra en su trabajo Jaén (2015), basada en la arqueología del conflicto. La programación de itinerarios didácticos para que los alumnos se acerquen a los vestigios y paisajes de la guerra, los investiguen y exploren con personas que convivieron que ellos, podría ser una buena herramienta para acercarles a este periodo de nuestra historia reciente.

\subsubsection{Conocimiento de la educación española a lo largo del siglo XX}

El último ítem del cuestionario trataba de valorar el grado de satisfacción del alumnado participante en el proyecto con la posibilidad que este les había ofrecido para tener un conocimiento más preciso de cómo había evolucionado la educación española a lo largo del siglo Xx. Ante esta pregunta más del $80 \%$ de los estudiantes consideran estar "muy de acuerdo", un 14,4\% afirman estar "de acuerdo" y menos de un $4 \%$ no muestran estar «ni de acuerdo ni en desacuerdo». El gráfico 5 recoge sus respuestas:

Gráfico 5. Respuestas de los estudiantes al ítem 5 del cuestionario de valoración del proyecto

5. El proyecto ha favorecido $\mathrm{mi}$ aprendizaje en el conocimiento de la educación española a lo largo del siglo XX

- Totalmente de acuerdo $=$ De acuerdo $=$ Ni de acuerdo ni en desacuerdo $\mathbf{m}$ En desacuerdo $\mid$ Totalmente en desacuerdo

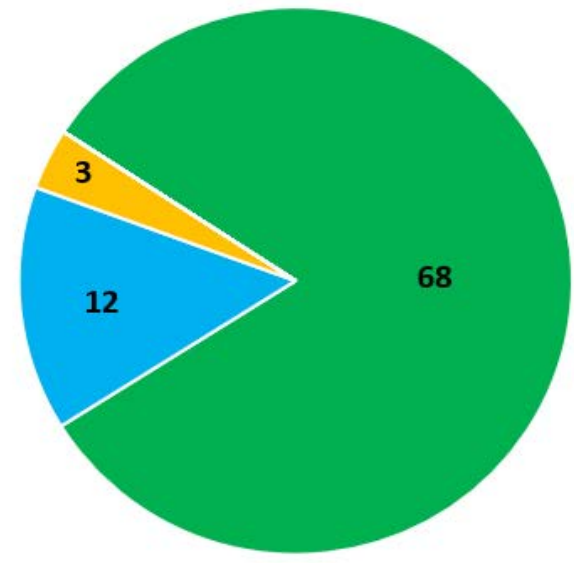

Si analizamos este ítem atendiendo a la variable "sexo», vemos cómo la media de las respuestas ofrecidas por los hombres $(4,90)$ es en este caso superior a la de las mujeres $(4,76)$. Curiosamente fueron los alumnos los que al comenzar el proyecto parecían tener un desconocimiento mayor del periodo de la Guerra Civil y lo que supuso el conflicto bélico para las generaciones que lo padecieron. Sus informes reflejan las conexiones que el proyecto les ha permitido establecer entre los distintos periodos en los que se divide la historia española del siglo Xx. 
A través de la práctica he podido diferenciar un poco más los acontecimientos que ocurrieron el siglo pasado. En los debates hablamos de los cambios que se produjeron tras la guerra y lo que ocurrió después y esto me hace ver la historia pasada de otra manera (Informe, M, CPEI).

Coincidiendo con investigaciones como la de Benadiba y Plotinsky (2008), el proyecto da muestras de cómo el trabajo con fuentes orales en el aula nos permite superar las dificultades que el alumnado tiene para la comprensión de los conceptos históricos y sociales. Además, la consulta de fuentes hemerográficas durante las primeras fases del proyecto fue importante para que los estudiantes se adentraran en el conocimiento de la institución educativa española de mediados del siglo XX y comprendieran la ruptura que supuso la Guerra Civil con las directrices educativas marcadas por el gobierno republicano.

El proyecto nos ha servido para ver cómo cambió todo con la guerra. La legislación educativa del franquismo no tenía nada que ver con la dictada por el gobierno de la República y ese cambio también se ve en las entrevistas (Informe, M, CPEI).

Desde la variable "asignatura», la media de respuestas del alumnado de Corrientes Pedagógicas de la Educación Infantil $(4,82)$ es sensiblemente superior a la ofrecida en la asignatura de Educación para la Paz y la lgualdad $(4,73)$. Consideramos que estas respuestas pueden venir de algún modo condicionadas por los propios contenidos de las asignaturas, pues en la primera de ellas, uno de los bloques trata expresamente de aproximar a los estudiantes a la educación española del siglo $\mathrm{xx}$, por lo que el proyecto les ha permitido tener una conexión directa con varios contenidos abordados en el aula.

Como ocurría en el trabajo de Mendioroz-Lacambra (2016), los estudiantes pusieron de manifiesto a través de sus informes, cómo antes de llevar a cabo el Proyecto, confundían hechos históricos, tenían importantes errores conceptuales y cronológicos y manifestaban algunos problemas para interrelacionar las diferentes etapas del siglo XX, aspectos que fueron mejorados durante el desarrollo del Proyecto.

\subsection{Visión general y aprendizajes de la práctica realizada}

\subsubsection{Aprendizajes de la práctica realizada}

Uno de los aprendizajes más importantes que los estudiantes destacan del proyecto es la importancia de establecer puentes intergeneracionales para conectar pasado y presente. Curiosamente, estos mismos aprendizajes se han encontrado en otros talleres de memoria histórica, como el realizado por Benadiba y Plotinsky 
(2008) en España y Argentina. Sin duda, las relaciones que se establecen entre los entrevistados, que portan la experiencia vivida, y el alumnado, que recibe de manera activa el recuerdo elaborado desde el presente de aquella experiencia, convierte para ellos el pasado en una «historia reciente» (p. 158).

Este fue un hecho que desgraciadamente ocurrió en nuestro país no hace muchos años, pero que muchas personas lo ven muy lejano y no le muestran la suficiente atención que se merece, a pesar de que forma parte de nuestra historia más reciente. Muchos, incluido yo, hemos desaprovechado la oportunidad de preguntar a personas de nuestro entorno cómo vivieron la guerra, y es un aspecto que tendríamos que cambiar y aprovechar sus vivencias, porque estos "niños de la guerra», actualmente son ancianos que están deseando manifestar todo lo que saben y nadie los escucha (Informe, H, EPI).

Coincidiendo con otro trabajo de Laura Benadiba (2011), vemos cómo estas relaciones intergeneracionales también contribuyen a la formación de la identidad de los participantes. La posibilidad que les ofrece el uso de estas fuentes para debatir con padres, abuelos, vecinos y otras personas allegadas influye en sus modos de entender el pasado y adquiere un valor importante tanto en el plano educativo como en el social. Sin duda, esta experiencia los lleva a criticar el desprecio con el que han sido tratados ciertos sectores de la población para narrar este pasado reciente.

Otro de los aprendizajes más visibles a través de los informes de los participantes y que coincide con otros estudios en los que se trabaja la historia oral con docentes en formación (Bilbao, Pérez y Ezkurdia, 2014), es que esta forma de trabajo ha conllevado un abundante número de aprendizajes interdisciplinares complejos. Los estudiantes son capaces de conectar la experiencia de las personas protagonistas con temas como los derechos humanos, la educación para la desobediencia e incluso la globalización.

El último aprendizaje que destacamos, por el interés que presenta para las asignaturas que participan en el proyecto, es que el trabajo de los estudiantes a través de la historia oral aumenta su motivación por el conocimiento del pasado y despierta en ellos un compromiso por la enseñanza de una historia, asentada en una postura feminista, que defiende la deconstrucción de convenciones académicas e intelectuales excluyentes (Hernández, 2011).

\subsubsection{Sentimientos provocados tras la realización de la entrevista oral}

La construcción del documento oral -la entrevista-, su transcripción y análisis han generado entre los estudiantes una serie de sentimientos que quedan marcados en su aprendizaje y su memoria. Las entrevistas no solo suponen para ellos 
un significado cognitivo, sino también afectivo, aspecto tratado en algunas investigaciones como la de Benadiba (2011) en las que se percibe, igual que en nuestro estudio, cómo las respuestas afectivas de los alumnos tienen una gran incidencia en la significatividad de sus aprendizajes.

Escuchar a una persona que ha vivido un periodo de guerra y que cuenta cosas tan personales me ha impactado mucho. No podemos infravalorar en absoluto las cosas que ha contado, la vida tan dura que les ha tocado vivir, los recursos tan escasos que tenían, cómo se buscaban la vida para conseguir comida, salir adelante etc. (Informe, $\mathrm{M}, \mathrm{CPEI})$.

A través de sus informes hemos podido comprobar esa sensibilización y conciencia crítica de la que hablaba Benadiba (2015) al construir conocimiento a partir de testimonios directos de personas que vivieron el proceso histórico que estamos investigando.

Los estudiantes revelan cómo el proyecto ha favorecido la posibilidad de conectar el presente y el pasado, de aumentar su motivación e interés por temas históricos y de darse cuenta del valor de la fuente oral para la reconstrucción de ciertos hechos pasados marcados por la ausencia de fuentes.

Al principio solo piensas que es un trabajo, tú grabas a la persona, lo transcribirás y lo entregarás, pero poco a poco mientras te cuentan la historia te empiezas a meter en el papel del hombre, a imaginarte cómo era la ciudad donde estás viviendo en ese momento y un montón de cosas que hacen que se convierta en algo más que una entrevista. La persona a la que estás entrevistando está compartiendo un pedazo de su vida, probablemente uno de los más duros que haya podido vivir en toda su larga vida y como toda persona le intentas comprender y siempre con miedo de citar alguna pregunta donde se pueda sentir ofendido o haga que recuerde cosas que no quiere pensar (Informe, H, EPI).

Pero, además $-\mathrm{y}$ coincidiendo con otras investigaciones como la de Sarria (2008)- hemos comprobado cómo la entrevista supone una serie de sentimientos interesantes de analizar tanto para el alumnado como para quienes regalan su experiencia. Para los primeros, la realización del proyecto ha servido para poder salir de esos cánones de la enseñanza reglada a la que suelen estar acostumbrados y que han marcado sus experiencias escolares desde la infancia. Para las personas que han compartido sus relatos, la práctica les ha hecho sentirse, como explican los propios alumnos, como partícipes de una sociedad que a menudo ha condenado sus experiencias al olvido. Su interés por el proyecto se ha visto reflejado en compartir con los estudiantes no solo su vivencia, sino también algunas fotografías, libros escolares y enseres personales que les recordaban aquella infancia lejana. 


\subsubsection{Relaciones del proyecto con el futuro profesional de los maestros en formación}

Explica Mendioroz-Lacambra (2016), que uno de los objetivos del área curricular de Educación Infantil "Conocimiento del Entorno» está estrechamente vinculado con la necesidad de que los docentes del Grado en Educación Infantil estén capacitados para entender la sociedad de manera crítica y responsable. Por ello, resulta fundamental que el alumnado universitario elabore significados sociales, construya identidades individuales y sociales de manera inclusiva, e interprete la historia como proceso en permanente construcción del que forma parte activa, llenando de contenido el tiempo (p. 400).

Con el Proyecto se ha demostrado, como en otras investigaciones como la de Benadiba (2007), que la enseñanza a través de fuentes orales favorece el desarrollo de una conciencia histórica que permite la formación de ciudadanos conscientes, críticos y participativos. Esta conciencia permite que los individuos tengan una percepción clara de su propia historicidad e identidad, aspecto que les permitirá actuar y proyectarse concreta y efectivamente en la sociedad en la que viven. Los informes recogidos nos permiten ver cómo el alumnado ha llevado a cabo a lo largo del proyecto ese proceso de conciencia crítica ante la construcción de la historia.

Quizá, algo común a las tres personas entrevistadas y que me hizo reflexionar fue cómo al contar las difíciles y duras situaciones que vivieron sienten ese dolor que en ocasiones no pueden evitar condensar en lágrimas. Sin duda, esos sentimientos son los que te hacen ver lo que de verdad fue la guerra y tomar conciencia del lamentable error que supuso. Esto es algo que los libros de historia no muestran, ya que se centran en números, fases y batallas dejando de lado el componente más importante de una guerra, el humano. Es importante conocer esa evolución y componente político, sin duda, pero no podemos dejar de lado esas historias de "la gente de a pie», del pueblo, que son los verdaderos protagonistas. Creo que debemos concienciarnos de la importancia de esa intrahistoria que es la base de lo que comúnmente llamamos Historia (Informe, H, EPI).

En línea con las afirmaciones realizadas por Molina-Neira (2017) podemos afirmar que el proyecto ha sido capaz de formar docentes críticos, pues sus respuestas han reflejado algunas de las características de este modelo de ciudadanía, como por ejemplo: la empatía hacia los coetáneos; el respeto hacia las libertades y derechos de las personas; la curiosidad por las estructuras históricas, sociales, políticas y económicas del pasado; el compromiso y la solidaridad con el contexto local; o el rechazo hacia discursos contrarios a la libertad individual y los derechos humanos.

Otro aspecto importante en este punto y que resulta de interés para los futuros docentes es que se dieron cuenta de cómo el testimonio oral se transforma en una fuente muy valiosa que representa las maneras en las que los individuos y las sociedades han extraído un significado de las experiencias pasadas. Cuando el 
entrevistado recuerda, lo hace «desde el presente», por lo tanto, ese recuerdo no se relaciona necesariamente con lo que vivió (Benadiba, 2015, p. 92). Esto los lleva a pensar en el valor de la memoria y cómo esta selecciona los acontecimientos del pasado de acuerdo con una serie de complejos procedimientos en los que están muy presentes las emociones y las experiencias. Como maestros, su papel en la vida de los menores con los que convivan será crucial para la formación de su identidad y de su memoria, un aspecto que destacan y que les resulta interesante.

Por último, nos gustaría destacar cómo el proyecto les hace ver a los estudiantes el papel que como docentes en formación tienen, para contar en sus aulas otra versión de este pasado reciente a partir de lo aprendido.

Desde el punto de vista de un docente esta práctica te ayuda a que, en un fututo como profesor, puedas realizar alguna actividad para concienciar del daño que puede causar una guerra (Informe, H, EPI).

Ellos mismos apuntan que una buena forma de llevar esta experiencia del pasado a sus futuras aulas podría ser invitando a personas ancianas a contar sus vivencias. Resulta interesante ver cómo la fuente oral ha sido para ellos significativa y volverían a recurrir a ella para enseñar a su propio alumnado cómo se vivió España la Guerra Civil.

\section{ALGUNAS CONCLUSIONES SOBRE LA EXPERIENCIA}

A través del proyecto Vivir la infancia en tiempos de guerra hemos podido comprobar cómo el uso de la historia oral tiene importantes beneficios en la formación inicial docente. El contacto con las experiencias de testigos de la historia permite a los estudiantes despertar una mirada crítica ante los acontecimientos del pasado e incentiva su motivación e interés hacia temas históricos.

Dos eran los objetivos que nos proponíamos al comenzar este artículo: 1) analizar la influencia que para los estudiantes ha tenido el proyecto en el conocimiento de la Guerra Civil española y la educación de la infancia en el aquel periodo de nuestra historia reciente; y 2) valorar los sentimientos que les ha generado conocer a través de fuentes orales la historia de un periodo tan convulso como el que vivió España a finales de los años treinta del siglo xx y lo aprendido de este proyecto para su futura profesión.

Respecto al primer objetivo, a la luz de los resultados analizados, se avala la idea de que los proyectos con fuentes orales en las titulaciones de Magisterio inciden de manera positiva en el conocimiento de los futuros docentes sobre el pasado. En los informes de los estudiantes hemos podido comprobar cómo la experiencia del Proyecto para el conocimiento de la Guerra Civil española va haciéndoles conscientes 
de las formas de vida de la infancia durante el periodo bélico y las implicaciones educativas de la familia y la escuela como agentes de socialización primaria.

Además, las respuestas de nuestros estudiantes a lo largo del proceso nos muestran cómo van construyendo una visión crítica hacia los acontecimientos pasados y mostrando un posicionamiento político y social ante determinados hechos históricos, como la guerra y la posguerra, que para ellos toman ahora una nueva dimensión más real y palpable. Como en otros trabajos semejantes Benadiba y Plotinsky (2008); Grana y Alonso (2009); o Fuertes (2015), descubrimos que los docentes en formación, a través de este tipo de proyectos con fuentes orales, son capaces de situar mejor los acontecimientos históricos, tener una visión global del pasado y profundizar en el conocimiento del periodo a investigar.

Respecto al segundo objetivo que nos proponíamos, hemos descubierto cómo conocer la historia de la Guerra Civil a partir de testimonios vivos hace aflorar en nuestros estudiantes una serie de sentimientos y emociones que los acompañan durante su aprendizaje y condicionan su visión del pasado. Este tipo de estrategias didácticas para la enseñanza de la Historia son idóneas para favorecer la empatía, el diálogo y los vínculos entre pasado y presente (Feliu y Hernández, 2013).

La experiencia también resulta importante para contribuir a la mejora de su responsabilidad social como docentes en formación. Muchos de los estudiantes expresan en el informe final la responsabilidad que sienten tras la realización del proyecto de enseñar en un futuro próximo en sus aulas una historia justa capaz de dar voz a todos los colectivos en ella implicados. El acercamiento a una historia familiar y cercana favorece que el estudiante se sienta responsable de su cuidado y mantenimiento.

Además, es importante reflejar en este apartado que tras el proyecto los estudiantes presentan una mirada crítica hacia los acontecimientos ocurridos en el periodo de la Guerra Civil y se dan cuenta de cómo algunos materiales educativos, como los libros de texto, no representan fielmente la realidad vivida en aquellos años.

La sensibilización ante el conflicto español también les hace preocuparse por otros problemas a los que la infancia se enfrenta en nuestros días, como la inmigración, la violencia o la terrible situación de los menores refugiados, hechos que conectan pasado y presente y permiten que los futuros docentes se responsabilicen de su actuación como ciudadanos globales.

Los hechos destacados nos permiten concluir resaltando la importancia de enseñar a nuestros estudiantes la Guerra Civil española desde el despertar de esa "conciencia histórica» mencionada por Laville (2003) y Tutiaux-Guillón (2003) al inicio del artículo. Solo a través de esta podemos formar docentes capaces de unir pasado, presente y futuro y valorar su significado.

No queremos terminar este trabajo sin mencionar algunas limitaciones que marcan el estudio. Las más importantes son el número de participantes y la contex- 
tualización del proyecto. Precisamente estas limitaciones son las que nos permiten abrir nuevas líneas de trabajo entre las que se encuentran: desarrollar la experiencia con un número más amplio de alumnos y alumnas de la Universidad de Valladolid; e intentar promoverla en otras facultades de Educación, con el fin de explorar nuevos resultados y poder establecer comparaciones.

\section{REFERENCIAS BIBLIOGRÁFICAS}

Anadón, J. (2006). Fuentes domésticas para la enseñanza del presente: la reconstrucción de la memoria histórica dentro del aula. Iber. Didáctica de las Ciencias Sociales, Geografía e Historia, 50, pp. 32-42.

Andreu Mediero, B. (2017). Historia e identidad. Investigación en Didáctica de las Ciencias Sociales en la formación del Profesorado de Primaria, a través del uso de las fuentes orales y la migración. En R. Martínez Medina, R. García-Morís, y C. R. García Ruíz (coords.), Investigación en Didáctica de las Ciencias Sociales. Retos preguntas y líneas de investigación (pp. 16-74). Córdoba: Universidad de Córdoba y AUPDCS.

Becerra Mora, J. C. (2014). Historia y memoria: una discusión historiográfica. Pensar Historia, 5, pp. 59-71.

Benadiba, L. (2007). Historia oral, relatos y memorias. Buenos Aires: Maipue.

Benadiba, L. (2011). La Historia oral como recurso metodológico para que los estudiantes puedan apropiarse de su pasado reciente. Palabras y Silencios, 6(1), pp. 28-32.

Benadiba, L. (2015). Historia oral: reconstruir historias únicas desde la diversidad. Revista Confluências Culturais, 2(4), pp. 90-99.

Benadiba, L. y Plotinsky, D. (2008). "Vivir en dictadura». La historia oral y la enseñanza del pasado reciente. Clío \& Asociados: la historia enseñada, 12, pp. 153-162.

Bilbao Bilbao, B., Pérez Urraza, K. y Ezkurdia Arteaga, G. (2014). La investigación biográfica en la formación inicial de Magisterio: Las historias de vida como temática del Trabajo Fin de Grado de Educación Infantil y Primaria. Tendencias Pedagógicas, 24, pp. 85-97. 
Boyd, C. P. (2000). Historia patria: política, historia e identidad nacional en España, 1875-1975. Barcelona: Pomares-Corredor.

Boyd, C. P. (2006). De la memoria oficial a la memoria histórica: La Guerra Civil y la Dictadura en los textos escolares de 1939 al presente. En S. Juliá Díaz (Dir.), Memoria de la Guerra y del Franquismo (pp. 79-99). Madrid: Taurus.

Boyd, C. P. (2013). Los libros escolares. En J. Álvarez Junco (Coord.), Las historias de España. Visiones del pasado y construcción de identidad (pp. 439-561). Barcelona: Crítica-Marcial Pons.

Burke, P. (1999). Formas de hacer Historia. Madrid: Alianza Universidad.

Chartier, R. (2007). El pasado en el presente. Literatura, memoria e historia. Coherencia, 7(4), pp. 83-102.

Chávez Preisler, C. y Pagès Blanch, J. (2017). Didáctica de la Historia y enseñanza del pensamiento histórico en formación inicial de docentes de Secundaria en Chile. En R. Martínez-Medina, R. García-Moris y C. R. García Ruiz (Eds.) (2017), Investigación en Didáctica de las Ciencias Sociales. Retos, preguntas y líneas de investigación (pp. 73-82). Córdoba: Universidad de Córdoba.

Costa Araújo, H. y Magalhaes, M. J. (2001). Retazos de vidas. Perspectivas biográficas, profesoras y ciudadanía. Lisboa: Cadernos coeducação.

Cuesta, R. (2007). Los deberes de la memoria en la educación. Barcelona: Octaedro.

Díaz Sánchez, P. y Gago González, J. M. (2006). La construcción y utilización de las fuentes orales para el estudio de la represión franquista. Hispania Nova, 6, pp. $1-25$.

Feliu, M. y Hernández, X. (2013). Didáctica de la Guerra Civil española (Vol. 297). Barcelona: Graó.

Ferrando Puig, E. (2006). Fuentes orales e investigación histórica. Orientaciones metodológicas para crear fuentes orales de calidad en el contexto de un proyecto de investigación histórica. Barcelona: Ediciones del Serbal.

Fuertes Muñoz, C. (2015). Las fuentes orales en la enseñanza de la Historia en la Educación Superior: exposición de una experiencia. CLIO. History and History teaching, 41, pp. 1-21. 
González Delgado, M. (2015). «Tiempo de Turbulencias»: La compleja representación de la Guerra Civil española en los libros de texto de Ciencias Sociales (19701990). Espacio, Tiempo y Educación, 2(1), pp. 163-185. doi: <http://dx.doi. org/10.14516/ete.2015.002.001.009>.

González, M.P. (2006). Conciencia histórica y enseñanza de la Historia: una mirada desde los libros de texto. Enseñanza de las Ciencias Sociales, 5, pp. 21-30.

Grana Gil, I. (2012). "La educación en tiempos de Franco» a través de las historias de vida. En P. L. Moreno Martínez y A. Sebastián Vicente (Eds.), Patrimonio y Etnografía de la escuela en España y Portugal durante el siglo XX, (pp. 483494). Murcia: Sociedad Española para el Estudio del patrimonio HistóricoEducativo (SEPHE) y Centro de Estudios sobre la Memoria Educativa (CEME) de la Universidad de Murcia.

Grana Gil, I. y Alonso Briales, M. (2009). La educación de las mujeres en Andalucía durante el franquismo a través de las historias de vida. En M. R. Berruezo Albéniz y S. Conejero López (Coords.), El largo camino hacia una educación inclusiva: la educación especial y social del siglo XIX a nuestros días (pp. 101112). Pamplona: Universidad Pública de Navarra.

Hartog, F. (2009). Historia, memoria y crisis del tiempo. ¿Qué papel juega el historiador? Historia y Grafía, 33, pp. 115-131.

Hernández Hernández, F. (2011). Las historias de vida en el marco del giro narrativo en la investigación en Ciencias Sociales: los desafíos de poner biografías en contexto. En F. Hernández, J. M. Sancho y J. I. Rivas (Coords.), Historias de Vida en Educación. Biografías en contexto (pp. 13-22). Universitat de Barcelona: Esbrina-Recerca.

Hernández Rodríguez, G., Iglesias Hernández, M. L. y Quintana Navarro, F. (1991). El taller de historia oral: memoria de una experiencia diferente. El Guiniguada, 2, pp. 319-338.

Jaén Milla, S. (2015). Los vestigios de la Guerra Civil Española: Espacios de interés para la Didáctica de las Ciencias Sociales. Didácticas Específicas,13, pp. 6-16.

Jiménez Ramírez, M. M. (2009). Historia oral en educación. Lo memorable del recuerdo, la importancia de la palabra. En M. R. Berruezo Albéniz y S. Conejero López (Coords.), El largo camino hacia una educación inclusiva: la educación 
especial y social del siglo XIX a nuestros días (pp. 719-726). Pamplona: Universidad Pública de Navarra.

Kirsch, G. E. (1999). Ethical dilemas in feminist research: the politics of location, interpretation and publication. Albany, NY: State University of New York Press.

Laville, C. (2003). Pour une éducation historique critique. Qu'attendre du courant de la consciencie historique? En N. Tutiaux-Guillon \& D. Nourrisson (Comps.), Identités, mémoires, conscience historique (pp. 13-25). Saint-Étienne: Publications de l'Université de Saint-Étienne.

Martínez Martín, I. y Ramírez Artiaga, G. (2017). Des-patriarcalizar y Des-colonizar la Educación. Experiencias para una formación feminista del profesorado. Revista Internacional de Educación para la Justicia Social, 6(2), pp. 81-95.

Martínez-Medina, R., García-Moris, R. y García Ruiz, C. R. (Eds.). (2017). Investigación en Didáctica de las Ciencias Sociales. Retos, preguntas y líneas de investigación. Córdoba: Universidad de Córdoba.

Mariezkurrena Iturmendi, D. (2008). La historia oral como método de investigación histórica. Gerónimo de Uztariz, 23/24, pp. 227-233.

Mendioroz-Lacambra, A. (2016). Propuesta formativa en el grado de maestro de Educación Infantil, para trabajar el método de investigación histórica en el aula. Arte, Individuo y Sociedad, 28(3), pp. 399-414.

Molina-Neira, J. (2017). Formar una ciudadanía crítica desde la enseñanza y el aprendizaje de la Historia: método, estrategias y contenidos clave. En P. Miralles Martínez, C. J. Gómez Carrasco y R. A. Rodríguez Pérez (Eds.), La enseñanza de la Historia en el siglo XXI. Desarrollo y evaluación de competencias históricas para una ciudadanía democrática (pp. 77-94). Murcia: Ediciones de la Universidad de Murcia.

Molinero Ruiz, C. (2006). ¿'Memoria de la represión o memoria del franquismo? En S. Julia (Dir.), Memoria de la guerra y del franquismo (pp. 219-277). Madrid: Taurus.

Moreu, A. C. (Coord.). (2010). Les fonts orals i audiovisuals en la història de l'educació. Innovació i recerca en la docència universitària. Barcelona: Universitat de Barcelona. 
Ortega Castillo, F. (2012). Los recuerdos escolares como núcleo de un proyecto docente en Historia de la Educación. En P. L. Moreno Martínez y A. Sebastián Vicente (Eds.), Patrimonio y Etnografía de la escuela en España y Portugal durante el siglo XX (pp. 495-504). Murcia: Sociedad Española para el Estudio del patrimonio Histórico-Educativo (SEPHE) y Centro de Estudios sobre la Memoria Educativa (CEME) de la Universidad de Murcia.

Pérez, A., Garguin, E. y Sorgentini, H. (Coords.). (2017). Formas del pasado: Conciencia histórica, historiografías, memorias. La Plata: Universidad Nacional de La Plata. Facultad de Humanidades y Ciencias de la Educación.

Rabazas, T., Ramos, S., Sgarbi, L. y Sonlleva, M. (2018). La educación primaria en la II República Española: Un análisis a través de testimonios de escolares. En S. González, J. Meda, X. Motilla y L. Pomante, La práctica educativa. Historia, Memoria y Patrimonio (pp. 649-661). Salamanca: FahrenHouse.

Redondo Castro, C. (2012). Las mujeres y la escuela. Relatos de tres generaciones: abuelas, madres e hijas. En P. L. Moreno Martínez y A. Sebastián Vicente (Eds.), Patrimonio y Etnografía de la escuela en España y Portugal durante el siglo XX (pp. 523-536). Murcia: Sociedad Española para el Estudio del patrimonio Histórico-Educativo (SEPHE) y Centro de Estudios sobre la Memoria Educativa (CEME) de la Universidad de Murcia.

Ricoeur, P. (2004). La historia, la memoria, el olvido. Buenos Aires: Fondo de Cultura Económica.

Robles Sanjuán, V. y Grana Gil, I. (2007). Transmisiones educativas generacionales: discursos sentimentales y conflictos de vida. En J. González-Agàpito y S. Marquès i Berta Noguer (Eds.), Resistència al franquisme i educación no formal: edició de les actes (pp. 299-314). Bañolas: Centre d'Estudis Comarcals de Banyoles.

Rodríguez García, A. M., Luque Pérez, R. M. y Navas Sánchez, A. M. (2014). Usos y beneficios de la historia oral. REIDOCREA, 3, pp. 193-200.

Sandín, M. P. (2003). Investigación cualitativa en educación. Madrid: McGraw-Hill.

Sarria Gómez, C. (2008). Un archivo de historia oral como herramienta didáctica. Hekademos, 1, pp. 5-22.

Sonlleva Velasco, M., Sanz Simón, C. y Rabazas Romero, T. (2018). Oralidad y patrimonio histórico-educativo. La memoria escolar de las generaciones 
instruidas en el franquismo. RIDPHE_R. Revista Iberoamericana do Patrimônio Histórico-Educativo, 2(4), pp. 306-324.

Soria López, G. M. (2015). El pensamiento histórico en la educación primaria: estudio de casos a partir de narraciones históricas. Enseñanza de las Ciencias Sociales, 14, pp. 83-95.

Thompson, P. (1988). La voz del pasado. Historia oral. Valencia: Edicions Alfons El Magnànim.

Traverso, E. (2010). Historiar la memoria. Revista Viento Sur, 113, pp. 79-83.

Tribó, G. (2005). Enseñar a pensar históricamente. Los archivos y las fuentes documentales en la enseñanza de la historia. Barcelona: Ice-Horsori.

Tutiaux-Guillón, N. (2003) L'histoire enseignée entre coutume disciplinaire et formation de la conscience historique: I'exemple français. En N. Tutiaux-Guillon, N. \& D. Nourrisson (Comps.), Identités, mémoires, conscience historique (pp. 27-41). Publications de l'Université de Saint-Étienne.

Valls, R. (2008). Enseñanza de la Historia y textos escolares. Buenos Aires: Libros del Zorzal. 